\title{
The location of diapycnal mixing and the meridional overturning circulation
}

\author{
Jeffery R. Scott \\ Program in Atmospheres, Oceans, and Climate \\ Massachusetts Institute of Technology \\ Cambridge, MA 02139 \\ Jochem Marotzke \\ School of Ocean \& Earth Science \\ Southampton Oceanography Centre \\ Southampton, SO14 3ZH \\ United Kingdom
}

Submitted to Journal of Physical Oceanography

April, 2001

Corresponding Author address:

Jeffery R. Scott,

MIT Room 54-171 1, Cambridge, MA 02139

jscott@mit.edu, (617) 258-5745 


\begin{abstract}
The large-scale consequences of diapycnal mixing location are explored using an idealized threedimensional model of buoyancy-forced flow in a single hemisphere. Diapycnal mixing is most effective in supporting a strong meridional overturning circulation (MOC) if mixing occurs in regions of strong stratification, that is, in the low-latitude thermocline where diffusion causes strong vertical buoyancy fluxes. Where stratification is weak, such as at high latitudes, diapycnal mixing plays little role in determining MOC strength, consistent with weak diffusive buoyancy fluxes at these latitudes. Boundary mixing is more efficient than interior mixing at driving the MOC; with interior mixing the planetary vorticity constraint inhibits the communication of interior water mass properties and the eastern boundary. Mixing below the thermocline affects the abyssal stratification and upwelling profile, but does not contribute significantly to the MOC through the thermocline or the ocean's meridional heat transport. The abyssal heat budget is dominated by the downward mass transport of buoyant water versus the spread of denser water tied to the properties of deep convection, with mixing of minor importance. These results are in contrast to the widespread expectation that the observed enhanced abyssal mixing can maintain the MOC; rather, they suggest that enhanced boundary mixing in the thermocline needs to be identified in observations.
\end{abstract}




\section{Introduction}

Microstructure and tracer release measurements of diapycnal mixing in the ocean (Polzin et al. 1997; Ledwell et al. 1993; Ledwell et al. 2000) show that mixing is strongly localized, with diffusivities exceeding $10^{-4} \mathrm{~m}^{2} \mathrm{~s}^{-1}$ above rough bottom topography and an order of magnitude less above smooth abyssal plains and in the thermocline. The energy for the diapycnal mixing is thought to come from winds and tides (Munk and Wunsch 1998, hereafter MW98) and perhaps geothermal sources (Huang 1999). The strength of the meridional overturning circulation (MOC) in models depends strongly on the choice of the vertical or diapycnal diffusivity (Bryan 1987; Colin de Verdière 1988; Zhang et al. 1999). Hence, diapycnal mixing plays a crucial role in the dynamics of the MOC and of climate, because the MOC is an important transport agent of properties relevant for climate.

To date, there have been only a few model studies that specifically examine the dynamical consequences of mixing location. Using an idealized single-hemisphere ocean general circulation model, Cummins et al. (1990; hereafter CHG) parameterized vertical diffusivity as a function of the buoyancy frequency, effectively increasing mixing at depth, particularly below the thermocline. Cummins (1991; hereafter C91) examined the results of several additional runs with specified increased mixing below the thermocline. Using a similar model without wind-forcing, Marotzke (1997; hereafter M97) imposed mixing only along the boundaries and applied the results as a foundation for a self-contained theory predicting the strength of the MOC. Samelson (1998) applied localized mixing on the eastern boundary to an idealized wind- and buoyancyforced single hemisphere, planetary geostrophic model. Hasumi and Suginohara (1999) investigated the effects of enhanced mixing over topography in a global model, and Marotzke and Klinger (2000) analyzed the effects of equatorially asymmetric vertical mixing.

Here, we present a systematic and comprehensive exploration of spatially varying diapycnal mixing. We juxtapose various extreme scenarios, in that mixing is concentrated entirely at low or high latitudes; at the western boundary, the eastern boundary, or the interior; in or below the thermocline. To our knowledge, the MOC's sensitivity to mixing in so clearly identifiable regimes of the ocean has never been investigated. Our numerical results lead us to revisit advective-diffusive balance in the abyss, the deep-ocean heat budget, and how planetary vorticity conservation helps us to understand the MOC. Our configuration is very highly idealized, but we maintain that the single hemisphere ocean is an appropriate configuration to represent the fundamental dynamics of the MOC. 
This paper is organized as follows. In Section 2, we briefly describe the ocean model. The ramifications of mixing that is highly localized are examined in Section 3. In Section 4 we present experiments with depth-dependent diapycnal mixing and examine the deep ocean heat balance and the structure of the overturning cell. We conclude with a discussion and summary in Section 5 and Section 6, respectively.

\section{Model Description}

We employ the $z$-coordinate, primitive equation model MOM2 (beta version 2.0), as described in Pacanowski (1996). Default parameters are listed in Table 1, with any deviations noted in the text. The ocean configuration and forcing are identical to that in M97: the domain is a $60^{\circ}$ wide single hemisphere sector, ranging from the equator to $64^{\circ}$, with a constant depth of 4500 meters; temperature and salinity are forced using an identical, zonally uniform cosine profile, with peakto-peak amplitudes of $27^{\circ} \mathrm{C}$ and $1.5 \mathrm{psu}$, respectively, and a 30-day relaxation time constant. Given these identical forcing profiles, the model can be thought of as being forced by buoyancy. Higher-order effects from the non-linear equation of state are included in the model but are not thought to be important in the results presented here. Therefore, we do not distinguish between temperature and buoyancy. For simplicity, no wind stress is imposed. Horizontal resolution is $1.875^{\circ}$ zonally by $2^{\circ}$ meridionally, using 30 vertical levels ranging from 50 meters at the surface to 250 meters at the lowest level.

As in M97, diapycnal mixing is imposed in the columns adjacent to the north, south, east, and west sidewalls, and is set to zero elsewhere; this is thought to mimic the effect of enhanced mixing due to a sloping lateral boundary. Diapycnal mixing at the equator is a surrogate for the global integral of mixing throughout the rest of the world's oceans. Although there is evidence of enhanced mixing at the equator (Gregg 1987; Peters et al. 1988) and the dynamics there are unique due to the vanishing of the Coriolis parameter (Gill 1982), our choice of the equator for our southern wall is for practical reasons, as cross-equatorial flow involves complicated dynamics (Marotzke and Klinger 2000) that are beyond the scope of our investigation. To insure that equatorial dynamics were not important in our findings, we spun-up a run with the southern boundary mixing moved one grid cell northward (i.e., removed from the equator), with only minor differences resulting. 
TABLE 1. Summary of numerical parameters. Notice that the MOM 2 code implements diapycnal mixing through vertical diffusion, which is a reasonable approximation as the slope of isopycnals is small over much of the ocean. We employ MOM's full tensor option which adds the horizontal diffusive flux terms $\kappa \partial_{x}(T, S)$ and $\kappa \partial_{y}(T, S)$ so that diapycnal mixing is represented with sharply sloping or vertical isopycnals.

\begin{tabular}{lc}
\hline \hline \multicolumn{1}{c}{ Parameter } & Value \\
\hline Basin width, length & $60^{\circ}, 64^{\circ}$ \\
Basin depth & $4500 \mathrm{~m}$ \\
Horizontal, vertical viscosity & $3.3 \times 10^{4} \mathrm{~m}^{2} \mathrm{~s}^{-1}, 10^{-2} \mathrm{~m}^{2} \mathrm{~s}^{-1}$ \\
Horizontal, isopycnal diffusivity & $0 \mathrm{~m}^{2} \mathrm{~s}^{-1}, 10^{3} \mathrm{~m}^{2} \mathrm{~s}^{-1}$ \\
Diapycnal boundary, interior diffusivity $(\kappa)$ & $10 \times 10^{-4} \mathrm{~m}^{2} \mathrm{~s}^{-1}, 0 \mathrm{~m}^{2} \mathrm{~s}^{-1}$ \\
Isopycnal thickness diffusion & $10^{3} \mathrm{~m}^{2} \mathrm{~s}^{-1}$ \\
Longitude, latitude grid spacing & $1.875^{\circ}, 2^{\circ}$ \\
Number of levels & 30 \\
\hline Temperature, salinity restoring timescale & 30 days \\
Time step, momentum & $30 \mathrm{minutes}^{\circ}$ \\
Time step, tracers & 12 hours \\
\hline
\end{tabular}

For computation efficiency, some of the experiments were run at half resolution, i.e., $3.75^{\circ} \times 4^{\circ}$, 16 vertical levels. In these runs, the diapycnal mixing coefficient along the boundaries was decreased $50 \%$ for comparative purposes with the standard runs, and the horizontal viscosity was changed to resolve the Munk boundary layer at the new zonal grid spacing. In section 4, several of the experiments were run with highly vertical resolution (90 evenly spaced levels) in order to minimize any adverse numerical effects and to allow for a smoother representation of stratification. In several direct comparisons (not shown), model results did not differ significantly between similarly configured runs at different vertical and/or horizontal resolution.

All model runs were integrated to equilibrium, as defined by a basin-averaged surface heat flux of $5 \times 10^{-3} \mathrm{~W} \mathrm{~m}^{-2}$ or less, where practical, and/or when overturning is discernibly within $0.1 \mathrm{~Sv}$ 
of its final value. The spin-up procedure is as follows. The control run was integrated to equilibrium at coarse resolution from an isothermal, motionless ocean, interpolated to standard resolution and allowed to re-equilibrate. All other experiments were started from the control run (at either the standard or coarse resolution) or from the equilibrated state of another experiment.

In order to minimize numerical "wiggles" resulting from zero diapycnal mixing in the ocean interior, we employed MOM's flux corrected transport advection scheme, a non-linear compromise between upstream and central differences (Gerdes et al. 1991). In effect, this scheme minimizes numerical noise through the introduction of some diapycnal mixing. We maintain this scheme's supplementary mixing is inconsequential here, based on trial experiments using MOM's other advection schemes and from the results of runs with very weak boundary mixing. The reader is referred to M97 for a discussion of other numerical issues involved with the boundary mixing implementation

Before proceeding, some additional comments are in order regarding the boundary layers that occur in the model solution. Reasonable treatment of western boundary currents is possible, albeit using an unrealistic viscosity coefficient due to our coarse grid spacing. As noted in Huck et al. (1999), however, the parameterization of the lateral boundary conditions can influence the large-scale circulation. Here, two notable features of our solution-narrow upwelling along the eastern and western boundary and deep downwelling in the northeast corner-are enhanced by (or perhaps even caused by) by our use of no-slip side boundaries with Laplacian momentum dissipation. The so-called "Veronis effect" (Veronis, 1975) whereby a Cartesian implementation of diffusion is thought to effect spurious horizontal mixing in the western boundary, producing upwelling, does not occur here given our use of MOM's isopycnal mixing scheme. Huck et al. (1999) argue that the lateral boundary parameterization induces upwelling which in turn causes the Veronis effect, rather than vice-versa. Huck et al. also showed that the model solution differs when a linear frictional closure scheme for tangential velocity is introduced into the vorticity equation, such as proposed in Winton (1993). It is not clear which boundary parameterization is superior for the purpose of modeling the real ocean, given a lack of observational evidence and our limited understanding of eddy dissipation processes (see Huck et al. for a more complete discussion). An additional complication is that our coarse grid does not permit resolution of these narrow boundary layers. Despite this seeming miasma of issues related to boundary layer implementation, we believe the qualitative behavior observed in our experiments is robust, reflecting the fundamental thermodynamics of the large-scale circulation rather than local dynamical features specific to the model implementation. The effect of other omissions, particularly the absence of wind stresses and topography, is addressed in our discussion section. 


\section{Horizontal Location of Mixing}

\section{a. Boundary versus uniform mixing}

In the model runs of M97, boundary flows set up an east-west temperature gradient which, through thermal wind balance, supports a vigorous MOC. We have repeated M97's boundary mixing control run here; minor differences are due to our use of improved resolution and the isopycnal mixing scheme. As in M97, upwelling occurs all along the west wall (Fig. 1a), advecting dense deep waters into the thermocline. On the east wall (Fig. 1b), however, the vertical flow pattern is more complicated. Upwelling occurs at depth, but surface flow downwells to increasing depths at high latitudes. Since the downwelling surface water is relatively warm, the eastern wall is less dense than the western wall, providing the necessary shear for zonally integrated southward flow at depth and northward flow in the upper ocean.

The meridional mass transport stream function for the control run is shown in Fig. 2a. Over $5 \mathrm{~Sv}$ $\left(\mathrm{Sv}=10^{6} \mathrm{~m}^{2} \mathrm{~s}^{-1}\right)$, or almost half of the net mass transport, upwells adjacent to the equator, where diapycnal mixing is concentrated. To examine the effect of the boundary mixing parameterization, we equilibrated a run with uniform diapycnal mixing diffusivity of $1.15 \times 10^{-4} \mathrm{~m}^{2} \mathrm{~s}^{-1}$, i.e., that which produces an area-weighted diffusivity equivalent to that of the control run. Detailed analyses of a similarly configured uniform mixing run, albeit with cruder numerics, are presented in Colin de Verdière (1988). Superficially, the MOC of the uniformmixing run (Fig. 2b) shows little difference from the boundary mixing run. The maximum of the overturning stream function is $1.7 \mathrm{~Sv}$ less in the uniform case, reducing the ocean's northward peak heat transport from .55 to $.47 \mathrm{PW}$ ( $\mathrm{PW}=10^{15}$ watts). With mixing spread out more evenly over the low latitudes, a much smaller proportion of the upward mass transport flows adjacent to the southern boundary. As would be suggested by our discussion in the previous section, strong vertical flows are present along the east and west boundaries, even in the uniform mixing case. Some of this flow recirculates zonally without contributing to the MOC (see Bryan, 1987, for a diagnosis of the meridionally averaged circulation and its scaling behavior with vertical diffusivity), while some of western upwelling moves northward along isopycnals. As such, it is not immediately clear what component of these boundary flows is diapycnal.

To determine which boundary flows are directly induced by diapycnal mixing, presumably through advective-diffusive balance, and which are a largely a consequence of lateral boundaries, 
we ran an experiment where we expanded the region of diapycnal mixing to two boundary grid columns around the model sidewalls. For consistency, we decreased the magnitude of $\kappa$ by $50 \%$. In addition, we resolved the Munk boundary layer across two zonal grid points. As with the uniform mixing run, imposing mixing away from the boundaries results in a decreased maximum in the overturning streamfunction (not shown), although the reduction here is only $0.3 \mathrm{~Sv}$. Near the equator, both meridional grid columns with mixing show strong upwelling, as shown in Fig. 3a, while interior flows are very weak in the meridional-vertical plane. In low latitudes, there are two columns of strong upwelling at both the eastern and western boundaries (Fig. 3b). This result is consistent with Colin de Verdière (1988), who diagnosed that the primary balance in low latitudes was between diffusive heating and cold upwelling. Similarly, Samelson (1998) observed strong upwelling in low latitudes along the eastern boundary, where his mixing was concentrated. Although some upwelling is evident in two columns at the boundaries at midlatitudes (Fig. 3c), the magnitude is much larger in the columns directly adjacent to the boundary. At high latitudes, nearly all upwelling in the west occurs adjacent to the boundary, as shown in Fig. 3d; in the east, some upwelling is apparent in both columns, although there is a large disparity in the velocities, as in the mid-latitude section. These results suggest that the mixing at low latitudes, in effect, drives local upwelling through vertical advective-diffusive balance. At middle and high latitudes, where stratification is generally weak, a large percentage of the vertical flow at the east-west boundaries is the result of mass convergence and subsequently a component of the vertical flow is oriented along isopycnals.

\section{b. Low latitude mixing; mid-basin mixing}

Motivated by these results, we wish to examine whether mid- and high-latitude mixing plays any significant role in the dynamics of the MOC. Fig. 4a shows the meridional overturning streamfunction given boundary mixing from the equator to $36^{\circ} \mathrm{N}$, with no diapycnal mixing to the north. As compared to the control run (Fig. 2a), the center of the overturning cell is several hundred meters higher in the water column, but there are no apparent differences in the zonally averaged temperature profile and the difference in overturning maximum is only $0.3 \mathrm{~Sv}$. In addition, there are only slight differences in the east and west wall boundary layer flows in midand high-latitudes (not shown).

If we further concentrate all mixing at the equator (Fig. 4b), the maximum in overturning drops by $38 \%$ to $7.9 \mathrm{~Sv}$, as we have reduced the area of mixing from the previous low-latitude mixing experiment by $50 \%$. Thus, the sub-tropical mixing on the east and west walls does contribute in driving the MOC. This result is consistent with significant upwelling into the thermocline along 
these latitudes, as suggested by the overturning pattern in runs that include mixing in the subtropics, e.g., Figs. 2a and 4a.

As mentioned in the introduction, the results from recent microstructure measurements suggest elevated mixing in the water column above the mid-Atlantic ridge. To this end, we ran a variation on our control run where we moved the mixing on the eastern and western boundaries to two adjacent meridional strips down the middle of the ocean, preserving the area-averaged diffusivity. This experiment produced a similar pattern of overturning as the control run (not shown). However, consistent with other runs that imposed interior mixing, the overturning cell was slightly weaker, comparable in magnitude with the uniform mixing experiment.

\section{c. Highly localized mixing}

The previous results suggest that the MOC cell depends critically on the meridional distribution of diapycnal mixing, with the zonal distribution being less crucial. In this subsection we take these experiments to their logical extreme, localizing mixing to a single grid column, which also facilitates a more detailed examination of the dynamical significance of interior versus boundary mixing. The diapycnal diffusivity in the "mixing column" was chosen so that the area-weighted diffusivity in latitudes $0^{\circ}-36^{\circ} \mathrm{N}$ matched that of the control run. However, to control numerical difficulties we also added a background diffusivity of $0.1 \times 10^{-4} \mathrm{~m}^{2} \mathrm{~s}^{-1}$, the value typically assumed for the "pelagic diffusivity" (MW98). In a run with uniform diffusivity set at this background value, the overturning streamfunction maximum is $2.3 \mathrm{~Sv}$, considerably weaker than that observed in this set of experiments.

We equilibrated runs with the mixing column at three zonal locations - the western boundary, at mid-basin, and at the eastern boundary - and at latitudes ranging from $2^{\circ} \mathrm{N}$ to $50^{\circ} \mathrm{N}$. Consistent with the previous results, nearly all the MOC's upwelling occurs where mixing is located. Fig. $5 \mathrm{abc}$ shows the temperature and flow in the bottom layer, thermocline, and surface layer, respectively, for a mixing column that is located at $18^{\circ} \mathrm{N}$ along the western boundary. All plots show deep convergence and upper level divergence at the mixing column; note that in this configuration, the deep western boundary current is effectively short-circuited by the upwelling at the mixing column. Figs. 6 and 7 show a similar low-level convergence and upper-level divergence at the mixing column when it is situated at the eastern boundary or ocean interior, respectively. 
Fig. 8 shows the maximum in overturning streamfunction for the three series as a function of the mixing column latitude. As the mixing location moves further north, the MOC decreases in intensity, most noticeably when the mixing is located in the interior. Conversely, the circulation remains strongest when the mixing is located on the eastern boundary. There are three competing effects that are important here, which we address separately.

\section{i) SURFACE BOUNDARY CONDITIONS}

An examination of the surface temperature immediately suggests why all of the highly localized mixing experiments plotted in Fig. 8 produce weaker overturning than the control mixing run: where upwelling occurs, the surface is quite cold, approximately $10^{\circ} \mathrm{C}$ colder than neighboring grid points, so the diffusion of heat into the thermocline is far less efficient than in the less localized mixing runs. In the mid-basin, equatorial mixing run the surface anomaly in temperature is about $1{ }^{\circ} \mathrm{C}$ less than when the mixing is at the equatorial western or eastern boundary, consistent with its slightly stronger overturning circulation. To further test this hypothesis, we ran two additional experiments. First, we divided the mixing evenly between three equatorial columns located at the west, east, and mid-basin. As indicated by the ' $\star$ ' on Fig. 8 , the overturning circulation was $2 \mathrm{~Sv}$ stronger, consistent with the steady-state temperature at these three points being much closer to the restoring profile than in the single column mixing runs. Second, we changed the surface restoring time constant from 30 days to 2 days. With the mixing column located in the southwest corner, the circulation increased to match that of the control run (but since the mixing column experiments employ the weak pelagic background mixing, we caution that the nearly exact agreement is not quite as "clean" as this result might suggest).

As the mixing column moves north, the surface restoring temperature decreases, providing a simple explanation for the noted decrease in overturning strength. The dashed line in Fig. 8 is a plot of the observed model surface temperature for the eastern mixing series as a function of mixing column latitude, taken to the two-thirds power and then normalized to coincide with the maximum overturning at the equator (the decrease in surface temperature with latitude is similar for the western and mid-basin mixing series). This power law is chosen as the approximate functional dependence of maximum overturning on the high to low latitude temperature difference (Scott, 2000). We see that with western boundary mixing, the fall-off with latitude is close to that predicted by the decrease in surface temperature. However, at high latitudes the eastern boundary mixing series is stronger than predicted while the interior mixing series is 
weaker, suggesting that additional factors play a role in determining the overturning strength as the mixing latitude is varied.

\section{2) INTERIOR VS. BOUNDARY MIXING}

Dynamical considerations suggest a different behavior of the interior localized mixing runs, compared to the boundary mixing runs; in this subsection, we go through this - fairly involved chain of reasoning. In all cases, the mixing causes upwelling at the mixing locations; this upwelling must be fed by converging horizontal flow, ultimately by southward flow emanating from the deep-sinking locations. But the upwelling and meridional flow are also linked dynamically: Assuming a geostrophic ocean interior, the planetary geostrophic vorticity equation

$$
\beta v=f \frac{\partial w}{\partial z}
$$

implies that any deep convergence (producing upwelling and hence vortex stretching) must be balanced by northward flow. This connection exists for upwelling in the basin interior but not for upwelling at the side walls, where (1) would not be expected to be a good approximation (Stommel and Arons 1960, Spall 2000). The following considerations apply in a scenario that has the same amount of water upwelling in the interior as would upwell at the same latitude but at a wall.

When mixing is highly localized in the ocean interior, the magnitude of $\partial w / \partial z$ is quite large, producing a strong recirculation in both the abyss and in the thermocline, as shown in Figs. 7a and 7 b, respectively (see Pedlosky 1996, pp. 405-409, for an analytical treatment of a localized abyssal sink; see also Spall 2000). At both depths, the recirculation is associated with a warm anomaly extending westward from the mixing column. In the thermocline, vortex compression produces a recirculation of opposite sense as the flow at depth, consistent with anomalous warmth above the level of no motion. The upper level recirculation is supported geostrophically by the diffusive heat flux "trapped" between the mixing column and the western wall. The westward propagation of the anomaly is due to the $\beta$-effect, the dynamics of which are described in Stommel (1982) for a geothermally driven warm anomaly. Notice that the anomaly is not advected to the east wall, where it could instead support the MOC. 
To support a given rate of upwelling at different latitudes, the intensity of the warm anomaly scales as $f^{2} / \beta$, from (1) and the requirement that the anomaly be in thermal wind balance with $v$ at the upwelling location. As $f^{2} / \beta$ increases monotonically with latitude, an increasingly strong anomaly would be required, which however cannot be created. Thus, only weaker upwelling can be supported, and the difference between the mid-basin and boundary mixing series plotted in Fig. 8 grows sharply with mixing latitude.

\section{3) EASTERN VS. WESTERN BOUNDARY MIXING}

From thermal wind considerations alone one might expect diffusive warming on the eastern boundary to support a strong MOC, whereas it is not clear how warming on the western boundary can support even a weak MOC. In reality, the dynamics are more complicated than suggested by this argument. If the low-latitude thermocline is heated diffusively, whether in the east or west, a meridional temperature gradient exists at mid-latitudes in concert with strong zonal flow and subsequent downwelling on the eastern boundary. This downwelling is the main mechanism that warms the eastern boundary, thus helping to provide the shear necessary for the MOC. Note that the high-latitude flow and temperature structure is similar in the thermocline whether mixing is located in the west (Fig. 5b), east (Fig.6b), or mid-basin (Fig.7b).

Instead, it is at lower latitudes where the distinction between the eastern and western localized mixing runs is more apparent. Notice, first, that the MOC is confined to the north of the mixing latitude. When mixing occurs on the eastern wall, the deep western boundary current turns and flows eastward across the basin (Fig. 6a) at the latitude of the mixing column. The low-level convergence into the eastern boundary causes upwelling from the abyss and divergence in the thermocline, producing opposite (westward) flow across the basin (Fig. 6b). In order to support this flow geostrophically, it must be colder in the tropics, as this depth is above the level of no motion. It must remain warm northward of the mixing latitude, or else geostrophic eastward flow would occur; note the large tongue of water with temperature greater than $3^{\circ} \mathrm{C}$.

In contrast, when mixing occurs only at the western boundary, significant zonal flow does not occur at low latitudes (Fig. 5b). At this depth the temperature in the tropics is a full degree higher than with localized eastern mixing, yielding the result that the tropical thermocline is actually deeper in the run with smaller overturning. This may seem surprising, as it has long been assumed that the meridional overturning scales as the thermocline depth (Welander 1971), but the caveat here is that the overturning does not extend to these tropical latitudes. 
Building on these differences, we now address why the aforementioned disparity in the eastern and western mixing series increases with mixing latitude (Fig. 8). As the mixing column moves northward and $f$ increases, weaker flow is in thermal wind balance with a similar density gradient. With mixing on the western boundary, it becomes increasingly difficult for geostrophic currents to advect the diffusive warming over to the eastern boundary at mid-latitudes. Conversely, as mixing on the eastern boundary moves northward it approaches the site of warm water injection, forming a cohesive warm anomaly which supports the dominant circulation-an anticyclonic gyre above a deep cyclonic gyre - even as the mixing column moves quite far to the north.

Finally, we return to our comparison of the boundary mixing control run with the uniform mixing run. As with localized interior mixing, uniform mixing leads to horizontal recirculation (as evidenced by stronger western boundary currents) supported by a warm anomaly (or, equivalently, less anomalous cooling) on the western side of the basin interior, consistent with the modest reduction in the overturning maximum.

The wave-like pattern in Fig. 5b along the western boundary to the north of the mixing latitude is, to a lesser extent, present to the south of the mixing latitude when the mixing is located on the east (as shown in Fig. 6b). Since this behavior does not ostensibly affect the conclusions presented here, we did not investigate further whether we were in fact observing stationary Rossby waves or spurious "wiggles" related to contrast between the intense local and weak background diffusivities.

\section{Depth-dependent Mixing}

\section{a. Numerical results}

The preceding section investigated the response of the MOC to the horizontal location of mixing. Now we turn to the dependence on where in depth mixing occurs. We performed three additional runs, with vertical profiles of mixing given in Fig. 9: a weak thermocline mixing case, with our standard boundary mixing below 1000 meters and exponentially decaying boundary diffusivity toward the surface; a weak deep mixing case, retaining the standard boundary mixing in the top 1000 meters but exponentially decreasing the boundary diffusivity below; and a strong deep mixing case where the boundary mixing is exponentially increased below 1000 meters. Note that 
our choice of 1000 meters for the thermocline depth was determined a posteriori, based on results from the control experiment.

When mixing is decreased in the thermocline, the thermocline depth decreases and the maximum in overturning strength is reduced to $7.0 \mathrm{~Sv}$ (not shown). The model's meridional heat flux is also considerably weaker. The ramifications of this result, particularly in the context of thermodynamic considerations, are considered in our discussion section.

The overturning streamfunction for the weak deep mixing case is shown in Fig. 10a. The maximum in overturning strength decreases by only $0.2 \mathrm{~Sv}$ as compared with the control run (Fig. 2a), and there is no apparent change in the zonally averaged thermocline. However, upwelling at depth along the equator is much weaker, so that upwelling through the abyss is more evenly distributed meridionally rather than concentrated where mixing (albeit weak) is parameterized.

In contrast, the strong deep mixing run (Fig. 10b) gives rise to vigorous upwelling at the equator, producing a deep secondary maximum in overturning. Approximately $3 \mathrm{~Sv}$ upwells near the equator at depth but subsequently downwells in the sub-tropics. In as much as the equatorial upwelling through the thermocline here is similar to that in the control and weak deep mixing runs, the overturning maximum is increased by less than $1 \mathrm{~Sv}$. The maximum meridional heat transport in the three runs varies by less than $0.01 \mathrm{PW}$, again suggesting that any changes in the deep circulation do not affect the flow through the surface layer or thermocline.

Our strong deep mixing run is similar to those discussed in $\mathrm{CHG}$, although their parameterization of vertical diffusivity as a function of $N^{-1}$ implies increased mixing with depth within the thermocline. C91 performed several experiments with varied mixing at depth, although his profiles of vertical diffusivity exhibited a rather sharp increase at the base of the thermocline, in contrast to our slow exponential increase. In both these studies, the increase in deep abyssal diffusivity was an order of magnitude less than that here. Despite these differences in the implementation of deep mixing, all results concur that the meridional heat flux is not sensitive to deep mixing. In contrast with our study, however, the CHG and C91 results suggest that the maximum in overturning streamfunction can in fact be quite sensitive to deep mixing. To examine this disparity, we ran an alternate run with a more sharply increased diffusivity near the base of the thermocline (i.e., similar to C91's profile, although our increase was somewhat less steep than that indicated by his Fig. 1). Here, our model's MOC achieved a more significant increase than in our other runs, again with only a minor change in the meridional heat flux. 
Nevertheless, our maximum in overturning is less sensitive to deep mixing than in $\mathrm{CHG}$ and C91. Note that our secondary meridional cell is much stronger than that shown in CHG's Fig. 4a, which we attribute to our boundary mixing implementation. With strong equatorial mixing the secondary cell is quite distant from the high-latitude maximum in overturning, allowing for less superposition of the deep circulation and the large-scale buoyancy-driven overturning. It is also possible that their use of a Cartesian mixing scheme contributes to their sensitivity. For example, the maximum of the MOC is deeper in M97's Cartesian boundary mixing run than in our isopycnal mixing run. With a deeper maximum, more superposition with this secondary deep circulation is possible.

\section{b. Advective-diffusive balance and stratification}

That deep diffusivity plays so little role in setting the overall strength of the MOC is surprising, given the importance that has been attributed to abyssal mixing (Munk 1966, Polzin et al. 1997, MW98). To investigate what is going on, we first test whether pointwise vertical advectivediffusive balance,

$$
w \frac{\partial \rho}{\partial z}=\frac{\partial}{\partial z}\left(\kappa \frac{\partial \rho}{\partial z}\right)
$$

is valid. If we assume that $w$ and $\kappa$ are both constant with depth, (2) can be readily solved to yield:

$$
\begin{aligned}
& \rho^{\prime}(z)=\rho^{\prime}(0) \mathrm{e}^{\alpha z} \\
& \rho(z)=\rho(0)+\frac{\rho^{\prime}(0)}{\alpha}\left(e^{\alpha z}-1\right)
\end{aligned}
$$

where $\alpha=w / \kappa$. Plugging the density at the bottom boundary into (4) yields:

$$
\rho(-H)=\rho(0)+\frac{\rho^{\prime}(0)}{\alpha}\left(e^{-\alpha H}-1\right)
$$

If we assume several e-folding depths from the ocean surface to depth so as to neglect the exponential term in (5), (4) can be re-written as: 


$$
\rho(z)-\rho(-H) \approx \frac{\rho^{\prime}(0)}{\alpha} e^{\alpha z}
$$

Fig. 11a shows a comparison of $T(z)-T(-H)$ with $\partial T / \partial z$ for our "control" boundary mixing run. Both quantities are shown as measured at the western equatorial boundary (the behavior is qualitatively similar throughout the tropics). According to (3) and (6), both curves should be linear, with similar slope, when plotted on a log scale. Only in the upper 1500 meters does this appear to be true, however. The reason is clear from $w(z)$ at the equator (Fig. 11b): upwelling increases quasi-linearly from the abyss into the thermocline before abruptly falling off in the top few hundred meters. In contrast, the variation of $w$ is small over much of the thermocline,

roughly between $3-3.5 \times 10^{-6} \mathrm{~ms}^{-1}$, so exponential behavior is expected. It is readily shown that the model's stratification and $w$ are consistent with one-dimensional advective-diffusive balance, with the surface and bottom temperatures as boundary conditions; in fact, the resulting solution is nearly an exact match with the model's temperature profile. Thus, horizontal advection (i.e., due to sloping isopycnals) does not play any significant role in setting stratification in the tropics, except at the bottom boundary where $w(z)$ vanishes.

\section{c. Abyssal heat balance}

To understand how the steady-state dynamics are affected by deep mixing, it is useful to start by examining the abyssal heat budget as illustrated in Fig. 12. Downwelling water in the northeast corner is relatively buoyant (Marotzke and Scott 1999), producing a warm anomaly with associate cyclonic flow in the deep ocean. Some of the flow immediately turns and upwells along the eastern boundary; as illustrated in Fig. 1b, the strongest upwelling occurs adjacent to downwelling, tending to cool the eastern boundary higher in the water column (note the cold anomaly between $30-40^{\circ} \mathrm{N}$ on the eastern boundary in Figs. 5b, 6b, and $7 \mathrm{~b}$ ). Most of the flow however continues westward across the basin, passing near deep convection. In these model runs deep convection reaches the bottom in the northwestern corner, which is relatively stagnant (and therefore cold) because the upper western boundary current separates from the "coast" between $40^{\circ} \mathrm{N}$ and $50^{\circ} \mathrm{N}$. Deep convection is not a source of deep mass flux, so there is no divergence of flow to spread the water mass properties of the convectively mixed column. Because the site of deep convection is anomalously cold, the geostrophic flow is around rather than through this region, so horizontal advection is also ineffective at conveying its water mass properties. Rather, 
this cold water is spread through the deep ocean by the Gent and McWilliams (1990) mesoscale eddy parameterization (one way to quantify its effect is via a "bolus" downwelling at the deep convection site and a bolus upwelling in the warmer sectors of the deep ocean). Thus, both deep downwelling and deep convection play a role in determining abyssal water mass properties (see also Marotzke and Scott 1999; Huck et al. 1999).

The relatively minor role played by abyssal mixing in setting MOC strength through the thermocline stands in marked contrast to other recent discussions (e.g., MW98, Ledwell et al. 2000), so a careful analysis of the abyssal heat budget is warranted. To reconcile the abyssal heat budget, consider the signs of the relevant flux terms. Let us first consider the mixing processes. In steady state, convective mixing causes a heat loss, and diffusion produces a heat gain. In our control boundary mixing run, however, the contribution from both of these sources is small. Given that deep flow is around rather than through the site of deep convection, scant heat is convectively mixed out of the abyss. The heat gain from diffusion is also small, due to the model's weak stratification in the abyss.

The vertical advective heat gain in the abyss is proportional to the following expression:

$$
\int w T d A=\int_{\text {downwelling }} w_{\mathrm{D}} T_{\mathrm{D}}+\int_{\text {upwelling }} w_{\mathrm{U}} T_{\mathrm{U}}
$$

where the $U$ and $D$ subscripts refer to upwelling and downwelling, respectively. This term seemingly could be positive or negative, but we suggest it must yield a heat gain (i.e., $T_{\mathrm{D}}>T_{\mathrm{U}}$, and by continuity $\left.-w_{\mathrm{D}}=w_{\mathrm{U}}\right)$, unless there are other deep diabatic sources/sinks such as geothermal heating (Scott et al., 2001). The advective heat gain is largely balanced by the remaining term in the budget, namely a heat loss from the parameterization of mesoscale eddies along isopycnals, which leads to a bolus heat transport opposite that of the advective transport.

The insensitivity of the overturning maximum to deep mixing, as would be suggested by our numerical results, is consistent with our observation that diffusive heating is not a dominant term in the abyssal heat budget. On the other hand, the differences in flow through the abyssal as shown in Fig. 10a and 10b imply that the strength of deep mixing affects the density structure of the deep ocean. Figs. 13a and Fig. 14a show the temperature and stratification $(\partial T / \partial z)$ at the west and east sides of the equator, respectively, for the depth-dependent mixing runs. With strong deep mixing, the bottom water is slightly warmer in low latitudes, i.e., the tail end of the abyssal flow pathway, consistent with a larger diffusive heat flux to the bottom. Similarly, 
weaker diffusive fluxes leads to colder bottom water at low latitudes. The temperature at the deep convection site, which is linked to the coldest surface temperature, is little changed in both cases (not shown).

Surprisingly, the low-latitude abyss is less stratified in both the weak and strong mixing cases. With weak deep mixing, less heat is diffused downward, whereas in the strong mixing case diffusion is so efficient at mixing heat that the temperature gradient is degraded. This latter result is in contrast with $\mathrm{CHG}$ and $\mathrm{C} 91$, where stronger stratification with increased deep mixing was observed (our aforementioned alternate run with sharply increased diffusivity near the base of the thermocline was also more weakly stratified). However, when we scaled back the increase in deep mixing by an order of magnitude so that the area-weighted diffusivity at each vertical level was more similar to that in C91, we too observed increased stratification at depth. More specifically, the deep ocean stratification doubled, although stratification in the 1000 meters below the thermocline was weaker. We speculate that some "optimum" profile of could lead to a maximum stratification at depth, although further research along these lines is beyond the scope of this paper.

As suggested by the plots of meridional overturning streamfunction, upwelling at the equator varies considerably between deep mixing runs (Figs. 13b and 14b). A weaker diffusive flux requires less upwelling for steady-state balance, and therefore it is no longer necessary for such a large percentage of abyssal upwelling to occur at the equator. Conversely, in the strong deep mixing case the larger equatorial diffusive heat flux must be balanced by strong upwelling. Without sufficient mixing in the thermocline, however, this upwelling essentially "detrains" from the larger cell, flowing horizontally and downward away from the equator.

Our analysis of the abyssal heat budget also suggests an explanation for the differences in the behavior on the east and west (cf. Fig. 13 vs. Fig 14). Because the abyssal flow reaches the western boundary directly after being modified by the water mass properties of deep convection, diffusion has had less opportunity to alter the stratification. Thus, the stratification in the west is less affected by the magnitude of deep mixing. On the other hand, in the east the effect of deep mixing is much more pronounced. The ocean is virtually unstratified in the bottom 2000 meters in the weak mixing run, and stratification also falls off more sharply (as compared to the control run) in the strong mixing case.

Differences in the upwelling profile are consistent with thermal wind balance of the zonally averaged deep overturning circulation. More specifically, note that the western boundary 
upwelling in the weak deep mixing run is sharply reduced. As a result, some heat penetrates downward on the west (mixing may be weak, but is still non-zero), so the nearly unstratified eastern boundary is colder than the west throughout much of the abyss (Fig 15a). The resulting east-west temperature difference is such that zonally averaged southward flow increases from the bottom upward, consistent with the overturning pattern observed in Fig. 11a. In the strong deep mixing run, upwelling on the eastern boundary peaks higher in the water column as compared to the west, which in turn produces a dipole pattern east-west temperature difference at depth (Fig. $15 \mathrm{~b})$. The warmer eastern boundary near the bottom is necessary to support the shear required for the deep equatorial overturning cell, but the east must also be colder near the base of the thermocline in order to attenuate the northward flow associated with the top of this cell.

\section{Discussion}

We have presented a series of numerical experiments that explore the large-scale consequences of mixing location. Our single-hemisphere model is highly idealized, lacking wind forcing and topography, although we submit that our results provide context for speculation about the dynamics of real ocean.

Given the different processes thought to play a role in the steady state balance of the MOCconvection, rotation, and buoyancy forcing - it is not directly apparent why the strength of the MOC is a function of the diapycnal diffusivity magnitude and distribution. According to "Sandström's theorem" (Sandström 1908), given surface heating at a higher geopotential than cooling (neglecting the smaller geothermal heat fluxes at the ocean floor), the steady state ocean circulation should for all intents and purposes be motionless except in a thin upper layer. In other words, given heating in the tropics, the ocean should not be able to operate as a heat engine, extracting energy from the surface buoyancy forcing to maintain a strong MOC. However, Jeffreys (1925) argued that turbulent mixing could effectively lower the geopotential of heating, i.e., leading to horizontal temperature gradients at depth which would in turn lead to a vigorous circulation (see Colin de Verdière 1993, MW98, and Huang 1999 for a more thorough discussion of Sandström's theorem and the controversy surrounding its application to the ocean.).

In the model, we find that diapycnal (non-convective) mixing at mid- and high latitudes is not critical in order to generate a MOC, given that surface temperatures there are relatively low and hence diffusive heat fluxes are much weaker than in the tropics. Mixing at low-latitudes, where the surface temperature is high, is more efficient at diffusing heat beneath the mixed layer and 
hence more effective at driving the MOC. This result suggests that thermodynamic considerations of the ocean circulation are indeed fundamental: The strength of the MOC is a direct function of the surface heat input which diffuses into the thermocline. Diapycnal mixing in the tropical thermocline communicates the surface buoyancy fluxes into the interior, which in turn increases potential energy. In conjunction with convective mixing at high latitudes, the penetration of heat leads to horizontal temperature gradients beneath the surface. In geostrophic balance, these temperature gradients generate strong zonal flows into the eastern boundary that subsequently downwell, leading to an east-west temperature difference that provides the vertical shear necessary for the MOC (Zhang 1992; Colin de Verdière 1993; Marotzke 1997). This elucidation provides justification for the advective-diffusive scale depth in the classical Bryan and Cox (1967) and Welander (1971) scaling of the meridional overturning strength.

Mixing at depth is not required to generate deep flow, and has little effect on the strength of the circulation through the thermocline. Our model results suggest that deep downwelling waters are relatively buoyant, and to lowest order the abyssal heat balance is between advective transport (producing a heat gain) and cooling through the Gent and McWilliams (1990) parameterization of the effect of mesoscale eddies along isopycnals. Thus, the abyssal water mass properties are an average of the properties tied to deep convection and that of deep mass injection. The magnitude of deep mixing can affect the bottom water temperature, however. With very weak mixing, the abyss is colder and nearly homogeneous, and flow upwells quasi-adiabatically into the thermocline. Stronger mixing produces a warmer abyss and dictates that upwelling in the abyss occurs diabatically, where mixing is located. An interesting corollary is that the temperature at the base of the thermocline appears to be set by the temperature of the downwelling water (c.f. Fig. 1b).

An idea expressed MW98 is that diapycnal mixing in the abyss, resulting from the energy input of winds and tides, is fundamentally necessary to "pull" the deep circulation through the abyss. Our results suggest otherwise; from an thermodynamic standpoint, abyssal mixing is not necessary for a vigorous overturning circulation. Rather, the model results imply that the stratification of the real abyss may indicate that deep mixing in the world's oceans is present to some extent, allowing for diabatic upwelling of flow.

Dissipation of tides is thought to produce elevated mixing at depth near rough bottom topography (Polzin et al. 1997), and also several 100m above, presumably through upward internal wave propagation. Our results suggest that this enhanced deep mixing by itself is insufficient to support a strong MOC and heat transport; rather, elevated mixing must be found at 
thermocline depths. Recent microstructure measurements off Cape Hatteras indicate strong mixing at thermocline depths above rough bottom topography, although of very limited spatial extent (Toole and Polzin 1999). Similar measurements in the Gulf Stream, above gently sloping terrain, suggest only slightly elevated levels of mixing. To date, significant areas of elevated mixing in the thermocline have not been located.

In the real ocean, mixing at depth may play an additional role which is not addressed here, namely its capacity to homogenize water masses of different origin (e.g., North Atlantic Deep Water and Antarctic Bottom Water). Our results show that the deep circulation pattern induced by deep mixing (or lack thereof) is confined below the thermocline and does not transport any significant amount of heat, and therefore does not play a significant role in determining the oceanic meridional heat transport. Although the bottom water temperature is affected by the deep mixing, we suggest this has only minor impact on the meridional heat flux, in contrast with the argument put forth in Cummins et al. (1991) to explain this insensitivity. The maximum in the overturning streamfunction may be affected by deep mixing through superposition of the deep circulation with the surface-forced overturning, depending on the vertical profile of mixing in the abyss.

Comparison of boundary mixing with interior mixing indicates that planetary geostrophic vorticity balance in the interior, the cornerstone of the Stommel and Arons (1960) theory for the abyssal component of the large-scale overturning circulation, actually hinders the process leading to east-west density differences which can support the MOC through thermal wind shear. As required by conservation of planetary vorticity, vortex stretching or compression in the ocean interior is accompanied by meridional flow. Here, we find that vortex compression in the thermocline effectively restricts the communication of warms waters to the eastern boundary, and therefore interior mixing is less effective at driving a vigorous MOC than boundary mixing. With boundary mixing, where frictional effects enter the vorticity balance, heat penetration into the thermocline leads to stronger zonal flows which downwell to greater depth at the eastern boundary.

In part due to the lack of observed thermocline mixing, other ideas regarding the importance of the Southern Hemisphere in driving North Atlantic Deep Water production have recently been gaining favor. One possibility is that the winds over the Antarctic Circumpolar Channel (ACC) lead to enhanced mixing there, as discussed in Wunsch (1998). Using a general circulation model of an idealized ocean basin, Marotzke and Klinger (2000) found increased cross-equatorial transport with enhanced mixing in the Southern Hemisphere, consistent with our results that 
show upwelling occurs where mixing is located. However, if mixing is concentrated in the latitude band of the ACC, our model results suggest that this would not be effective in driving a strong MOC, as the cool surface temperatures would lead to weak diffusive heat flux penetrating into the thermocline.

Our standard boundary mixing is parameterized in vertical columns many kilometers wide, which provides an equal area of mixing at all depths. In the real ocean, the boundaries are more horizontal than vertical, and mixing likely occurs over a significantly reduced length scale normal to the boundary. Moreover, the effect of diapycnal mixing on sloping boundary has been shown to have dynamical consequences (Garrett 1991; Thompson and Johnson 1996), which may influence the large-scale circulation. The presence of sloping boundaries at high latitudes affects the volume of deep mass transport by requiring deep convection to occur in the open ocean (Spall and Pickart 2001), which may alter our depiction of the abyssal heat balance.

\section{Summary}

The main conclusions from our idealized experiments are:

i) Boundary mixing is more efficient than interior mixing in causing a strong MOC.

ii) The MOC strength through the thermocline, and the associated heat transport, are mainly determined by thermocline mixing at low latitudes, where the vertical temperature gradient is strong. In contrast, high-latitude and deep mixing play lesser roles.

iii) Mixing plays a minor role in the deep-ocean heat budget.

\section{Acknowledgements}

The authors thank Carl Wunsch, Kerry Emanuel, Barry Klinger, and Hua Ru for discussions and comments on an earlier version of this manuscript. JS was supported by the MIT Joint Program on the Science and Policy of Global Change and by the U.S. Department of Energy's Office of Biological and Environmental Research grant DE-FG02-93ER61677. JM was supported by NSF grant 9810800 . 


\section{References}

Bryan, F., 1987: Parameter sensitivity of primitive equation ocean general circulation models. $J$. Phys. Oceanogr., 17, 970-985.

Bryan, K., 1969: A numerical method for the study of the circulation of the world ocean. $J$. Comput. Phys., 4, 347-376.

Bryan, K., and M. Cox, 1967: A numerical investigation of the oceanic general circulation. Tellus, 19, 54-80.

Colin de Verdière, A., 1988: Buoyancy driven planetary flows. J. Mar. Res., 46, 215-265.

Colin de Verdière, A., 1993: On the oceanic thermohaline circulation. Modelling Oceanic Climate Interactions, J. Willebrand and D.L.T. Anderson, eds., NATO ASI Series, Springer, Berlin, 151-183.

Cummins, P., 1991: The deep water stratification of ocean general circulation models. Atmos.Ocean, 19, 563-575.

Cummins, P.F., G. Holloway, and A.E. Gargett, 1990: Sensitivity of the GFDL ocean general circulation model to a parameterization of vertical diffusion. J. Phys. Oceanogr., 20, 817830.

Garrett, C., 1991: Marginal mixing theories. Atmos.-Ocean, 29, 313-339.

Gent, P.R., and J.C. McWilliams, 1990: Isopycnal mixing in ocean circulation models. J. Phys. Oceanogr., 20, 150-155.

Gerdes, R.C., C. Köberle, and J. Willebrand, 1991: The influence of numerical advection schemes on the results of ocean general circulation models. Clim. Dyn., 5, 211-226.

Gill, A.E., 1982: Atmosphere-Ocean Dynamics. Academic Press, 662 pp.

Gill, A.E., and K. Bryan, 1971: Effects of geometry on the circulation of a three-dimensional southern-hemisphere ocean model. Deep-Sea Res., 18, 685-721.

Gregg, M.C., 1987: Diapycnal mixing in the thermocline: A review. J. Geophys. Res., 92, 52495286.

Hasumi, H., and N. Suginohara, 1999: Effects of locally enhanced vertical diffusivity over rough bathymetry on the world ocean circulation. J. Geophys. Res., 104, 23,367-23,374. 
Huang, R.X., 1999: Mixing and energetics of the oceanic thermohaline circulation. J. Phys. Oceanogr., 29, 727-746.

Huck, T., A.J. Weaver, and A. Colin de Verdière, 1999: On the influence of the parameterization of lateral boundary layers on the thermohaline circulation in coarse-resolution ocean models. J. Mar. Res., 57, 387-426.

Jeffreys, H., 1925: On fluid motions produced by differences of temperature and humidity. Quart. J. Roy. Meteor. Soc., 51, 347-356.

Ledwell, J.R., A.J. Watson, and C.S. Law, 1993: Evidence for slow mixing across the pycnocline from an open-ocean tracer release experiment. Nature, 364, 701-703.

Ledwell, J.R., E.T. Montgomery, K.L. Polzin, L.C. St. Laurent, R.W. Schmitt, and J.M. Toole, 2000: Evidence for enhanced mixing over rough topography in the abyssal ocean. Nature, 403, 179-182.

Luyton, J.R., J. Pedlosky, and H. Stommel, 1983: The ventilated thermocline. J. Phys. Oceanogr., 13, 292-309.

Macdonald, A.M., and C. Wunsch, 1996: The global ocean circulation and heat flux. Nature, 382, 436-439.

Marotzke, J., 1997: Boundary mixing and the dynamics of three-dimensional thermohaline circulations. J. Phys. Oceanogr., 27, 1713-1728.

Marotzke, J., and B.A. Klinger, 2000: The dynamics of equatorially asymmetric thermohaline circulations. J. Phys. Oceanogr., 30, 955-970.

Marotzke, J., and J.R. Scott, 1999: Convective mixing and the thermohaline circulation. J. Phys. Oceanogr., 29, 2962-2970.

Mauritzen, C., and S. Häkkinen: On the relationship between dense water formation and the "Meridional Overturning Cell" in the North Atlantic Ocean. Deep-Sea Res., 46, 877-894.

McDermott, D.A., 1996: The regulation of northern overturning by Southern Hemisphere winds. J. Phys. Oceanogr., 26, 1234-1255.

Munk, W., 1966: Abyssal recipes. Deep-Sea Res., 13, 707-730.

Munk, W., and C. Wunsch, 1998: Abyssal recipes II: energetics of tidal and wind mixing. DeepSea Res., 45, 1977-2010. 
Pacanowski, R.C., 1996: MOM 2.0 documentation, user's guide, and reference manual. GFDL Ocean Tech. Rep. 3.1, Geophysical Fluid Dynamics Laboratory/NOAA, Princeton, NJ. [Available from GFDL/NOAA, Princeton University, P.O. Box 308, Princeton, NJ 08542.]

Pacanowski, R.C., and G. Philander, 1981: Parameterization of vertical mixing in numerical models of the tropical ocean. J. Phys. Oceanogr., 11, 1142-1451.

Park, Y.-G., and K. Bryan, 1999: Comparison of thermally driven circulations from a depth coordinate model and an isopycnal layer mode: Part. I. A scaling law - sensitivity to vertical diffusivity. J. Phys. Oceanogr., 30, 590-605.

Pedlosky, J., 1996: Ocean Circulation Theory. Springer, 453 pp.

Peters, H., M.C. Gregg, and J.M. Toole, 1988: On the parameterization of equatorial turbulence. J. Geophys. Res., 93, 1199-1218.

Polzin, K.L., J.M. Toole, J.R. Ledwell, and R.W. Schmitt, 1997: Spatial variability of turbulent mixing in the abyssal ocean. Science, 276, 93-96.

Rahmstorf, S., 1995: Multiple convection patterns and thermohaline flow in an idealized OGCM. J. Climate, 8, 3028-3039.

Redi, M.H., 1982: Oceanic isopycnal mixing by coordinate rotation. J. Phys. Oceanogr., 12, 1154-1158.

Samelson, R.M., 1998: Large-scale circulation with locally enhanced vertical mixing. J. Phys. Oceanogr., 28, 712-726.

Sandström, J.W., 1908: Dynamische Versuche mit Meerwasser. Annals in Hydrodynamic Marine Meteorology, p. 6.

Scott, J.R., 2000: The roles of mixing, geothermal heating, and surface buoyancy forcing in ocean meridional overturning dynamics. Massachusetts Institute of Technology, Ph.D. thesis, $128 \mathrm{pp}$.

Scott, J.R., J. Marotzke, and A. Adcroft, 2001: Geothermal heating and its influence on the meridional overturning circulation. J. Geophys. Res., submitted.

Spall, M.A., 2000: Large-scale circulations forced by mixing near boundaries, J. Mar. Res., 58, 957-982. 
Spall, M.A., and R.S. Pickart, 2001: Where does dense water sink? A subpolar gyre example, $J$. Phys. Oceanogr., 31, 810-826.

Stommel, H., 1982: Is the South Pacific helium-3 plume dynamically active? Earth Planet Sci. Let., 61, 63-67

Stommel, H., and A.B. Arons, 1960: On the abyssal circulation of the world ocean - I. Stationary planetary flow patterns on a sphere. Deep-Sea Res., 6, 140-154.

Thompson, L., and G.C. Johnson, 1996: Abyssal currents generated by diffusion and geothermal heating over rises. Deep-Sea Res., 43, 193-211.

Toggweiler, J.R., and B. Samuels, 1995: Effect of Drake Passage on the global thermohaline circulation. Deep-Sea Res., 42, 477-500.

Toggweiler, J.R., and B. Samuels, 1998: On the ocean's large-scale circulation near the limit of no vertical mixing. J. Phys. Oceanogr., 28, 1832-1852.

Toole, J.M., and K.L. Polzin, 1999: A fine- and microstructure section across the continental slope and Gulf Stream. EOS, Transactions, American Geophysical Union, 80, OS124.

Veronis, G., 1975: The role of models in tracer studies. Numerical models of the ocean circulation, Nat. Acad. of Sciences, Washington DC, 14 pp.

Welander, P., 1971: The thermocline problem. Phil. Trans. Roy. Soc. London, A270. 415-421.

Winton, M., 1993: Numerical investigations of steady and oscillating thermohaline circulations, Ph.D. thesis, University of Washington, $155 \mathrm{pp}$.

Wunsch, C., 1996: The Ocean Circulation Inverse Problem. Cambridge University Press, $442 \mathrm{pp}$.

Wunsch, C., 1998: The work done by the wind on the ocean circulation. J. Phys. Oceanogr., 28, 2331-2339.

Zhang, J., R.W. Schmitt, and R.X. Huang, 1999: The relative influence of diapycnal mixing and hydrologic forcing on the stability of the thermohaline circulation. J. Phys. Oceanogr., 29, 1096-1108.

Zhang, S., C.A. Lin, and R.J. Greatbatch, 1992: A thermocline model for ocean-climate studies. J. Mar. Res., 50, 99-124. 
(a)
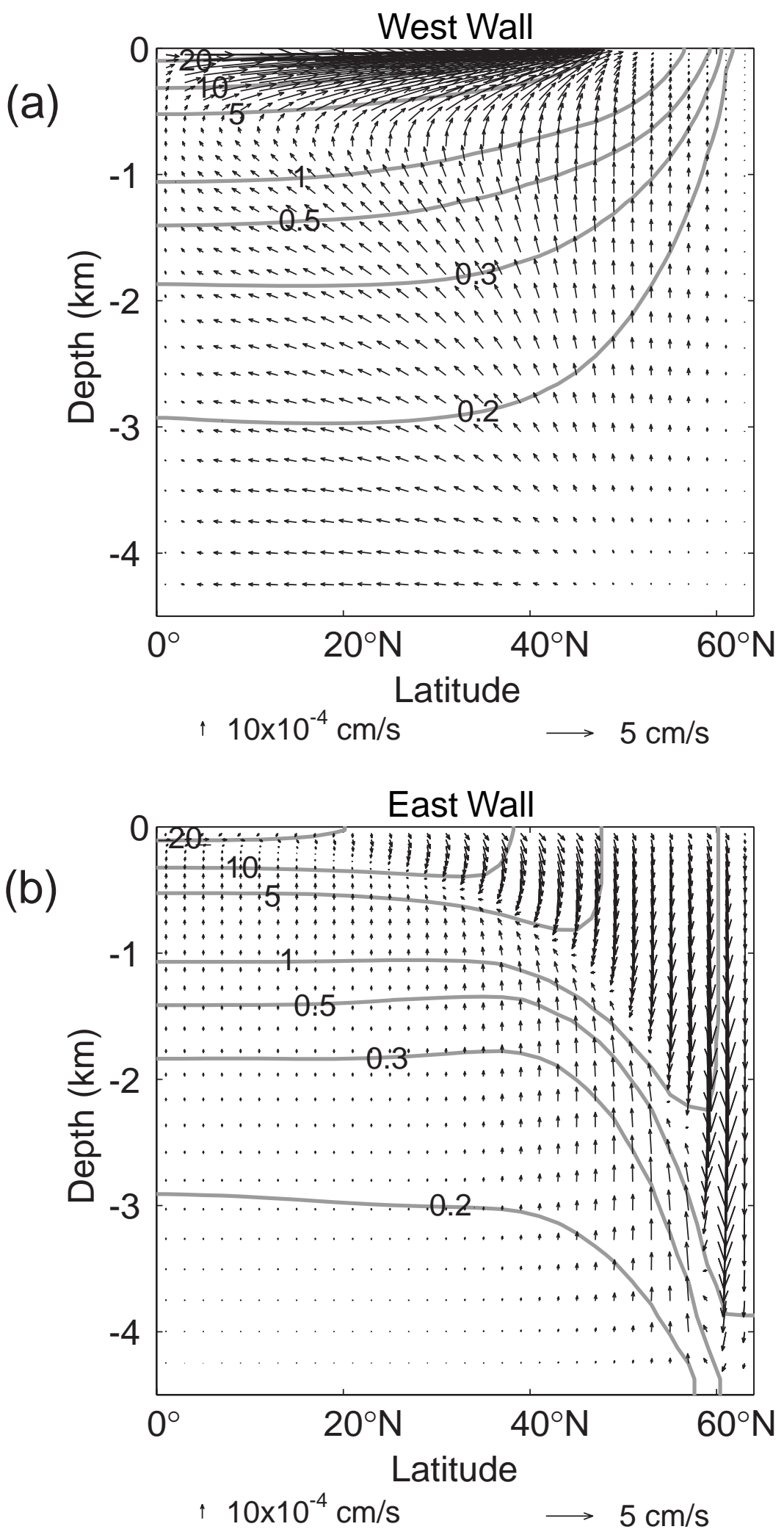

FIG. 1. Boundary mixing run, $\kappa=10 \times 10^{-4} \mathrm{~m}^{2} \mathrm{~s}^{-1}$. (a) Temperature (contour levels as indicated) and flow along the western wall; (b) temperature and flow along the eastern wall. Vertical and horizontal velocity scale is shown for reference. 

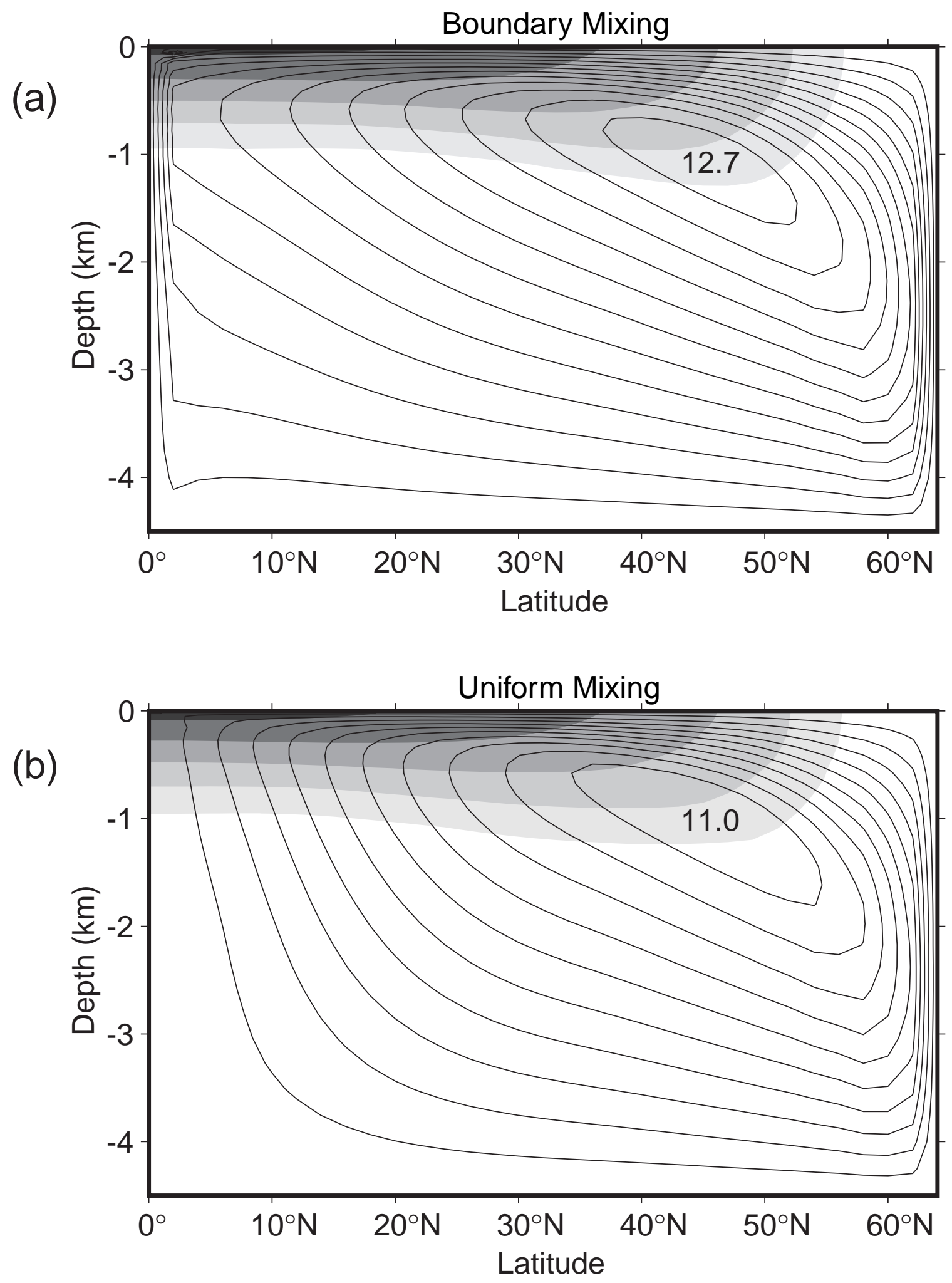

FIG. 2. Meridional overturning streamfunction (contours) and zonally averaged temperature (shading) for (a) boundary mixing run, $\kappa=10 \times 10^{-4} \mathrm{~m}^{2} \mathrm{~s}^{-1}$ and (b) uniform mixing run, $\kappa=1.15 \times 10^{-4} \mathrm{~m}^{2} \mathrm{~s}^{-1}$. In this and all subsequent plots of overturning streamfunction and zonally averaged temperature, overturning contours interval is $1 \mathrm{~Sv}$; isotherms are at $0.05,0.1,0.2,0.4$, and $0.8 \times \Delta T\left(\Delta T=27^{\circ} \mathrm{C}\right)$; flow is oriented clockwise around overturning maximum. 
(a)
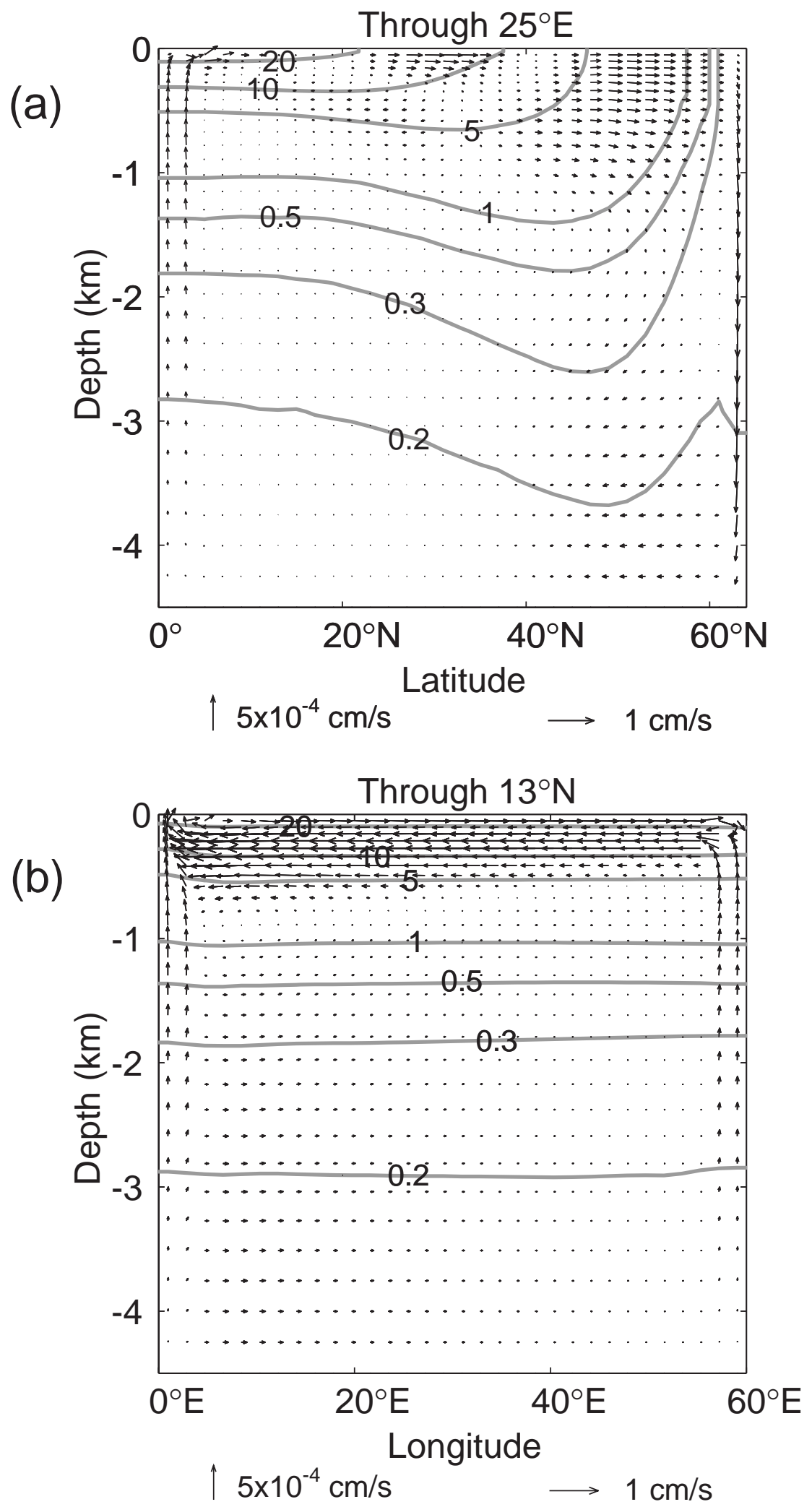

FIG.3. Two-column boundary mixing run, $\kappa=5 \times 10^{-4} \mathrm{~m}^{2} \mathrm{~s}^{-1}$. (a) Temperature and flow along the meridional plane through $25^{\circ} \mathrm{E}$; (b) temperature and flow along the zonal plane through $13^{\circ} \mathrm{N}$; (c) temperature and flow along the zonal plane through $35^{\circ} \mathrm{N}$; (d) temperature and flow along the zonal plane through $55^{\circ} \mathrm{N}$. 
(c)
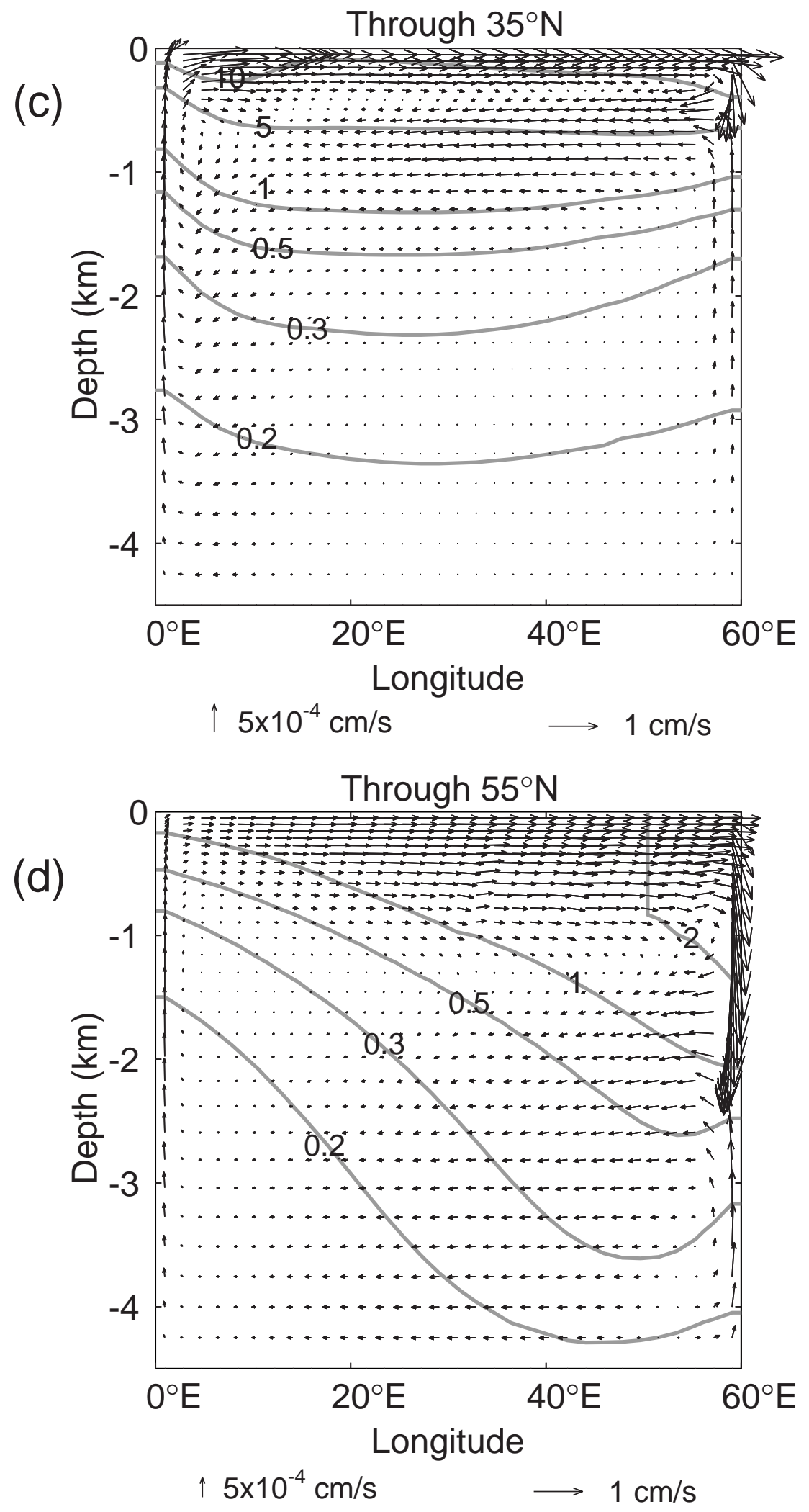
(a)

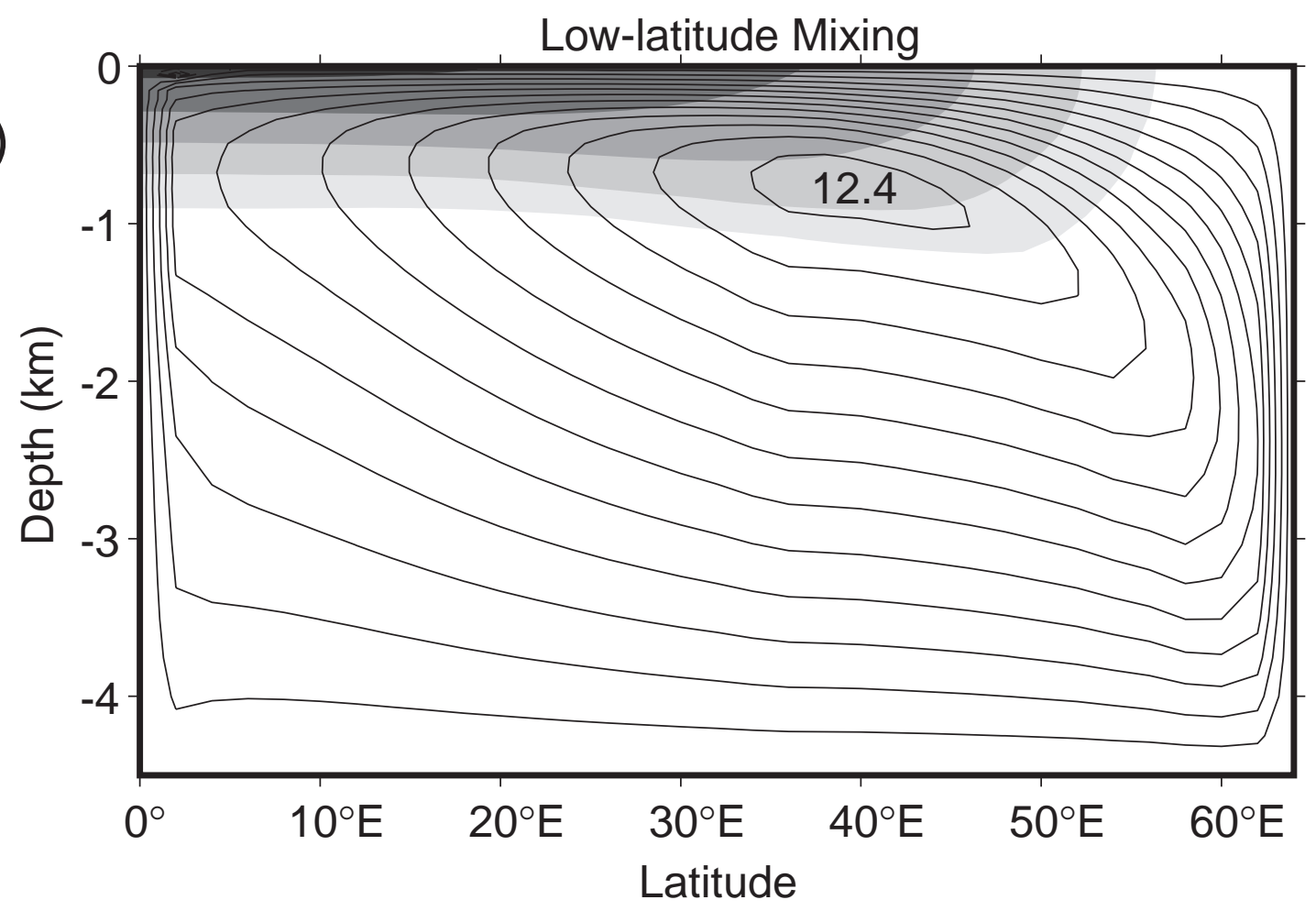

(b)

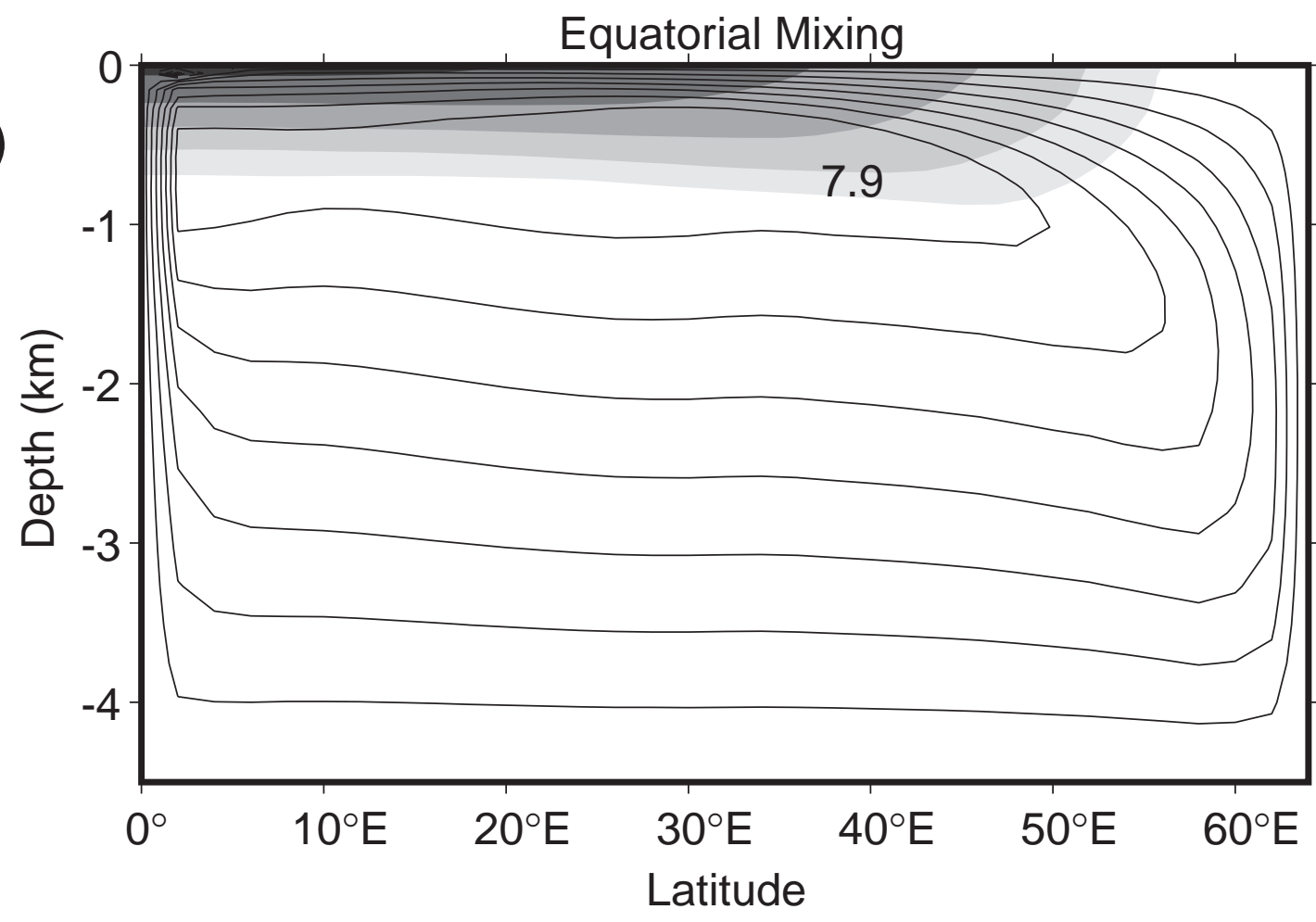

FIG.4. Meridional overturning streamfunction (contours) and zonally averaged temperature (shading) for (a) low-latitude boundary mixing run, $\kappa=10 \times 10^{-4} \mathrm{~m}^{2} \mathrm{~s}^{-1}$ between $0-36^{\circ}$ latitude, otherwise diffusivity is set to zero; and (b) equatorial mixing run, $\kappa=10 \times 10^{-4} \mathrm{~m}^{2} \mathrm{~s}^{-1}$ between $0-2^{\circ}$ latitude, otherwise diffusivity is set to zero. 

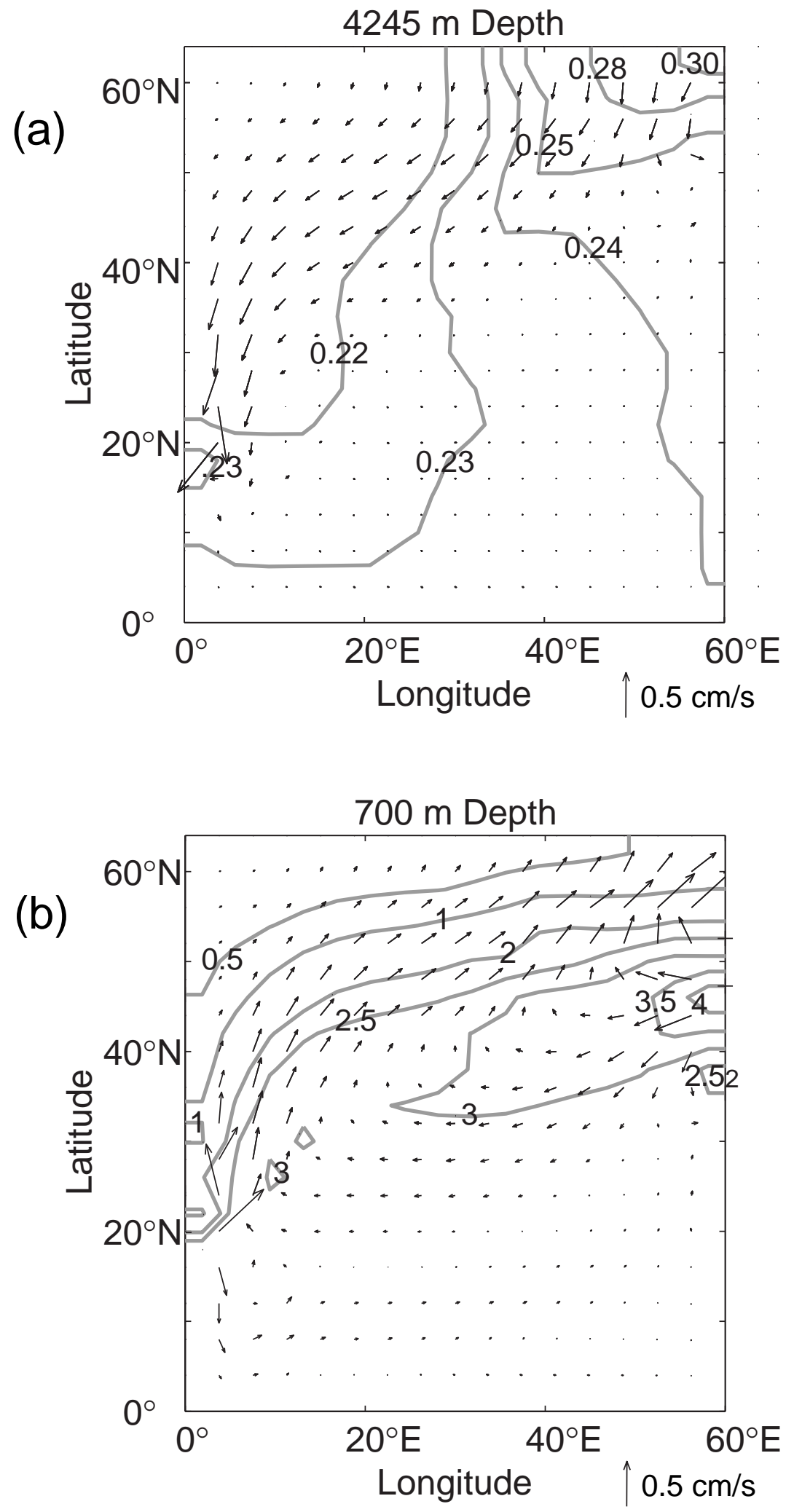


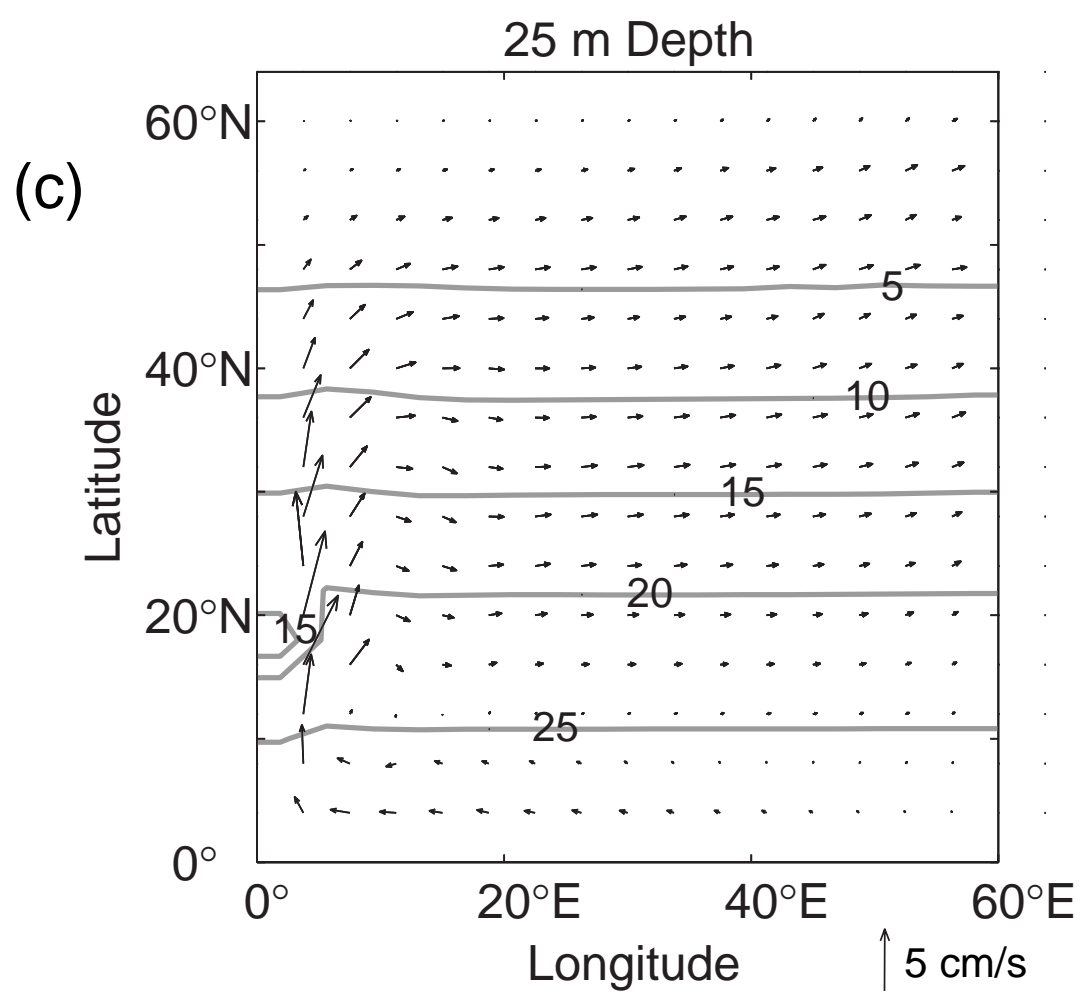

FIG.5. Plan view of the circulation and temperature (contours) with the mixing column located along the western boundary at $18^{\circ} \mathrm{N}$. (a) lowest model level (4245 m depth); (b) thermocline level (700 $\mathrm{m}$ depth); (c) uppermost model level (25 m depth). Velocity scales are shown for reference. 

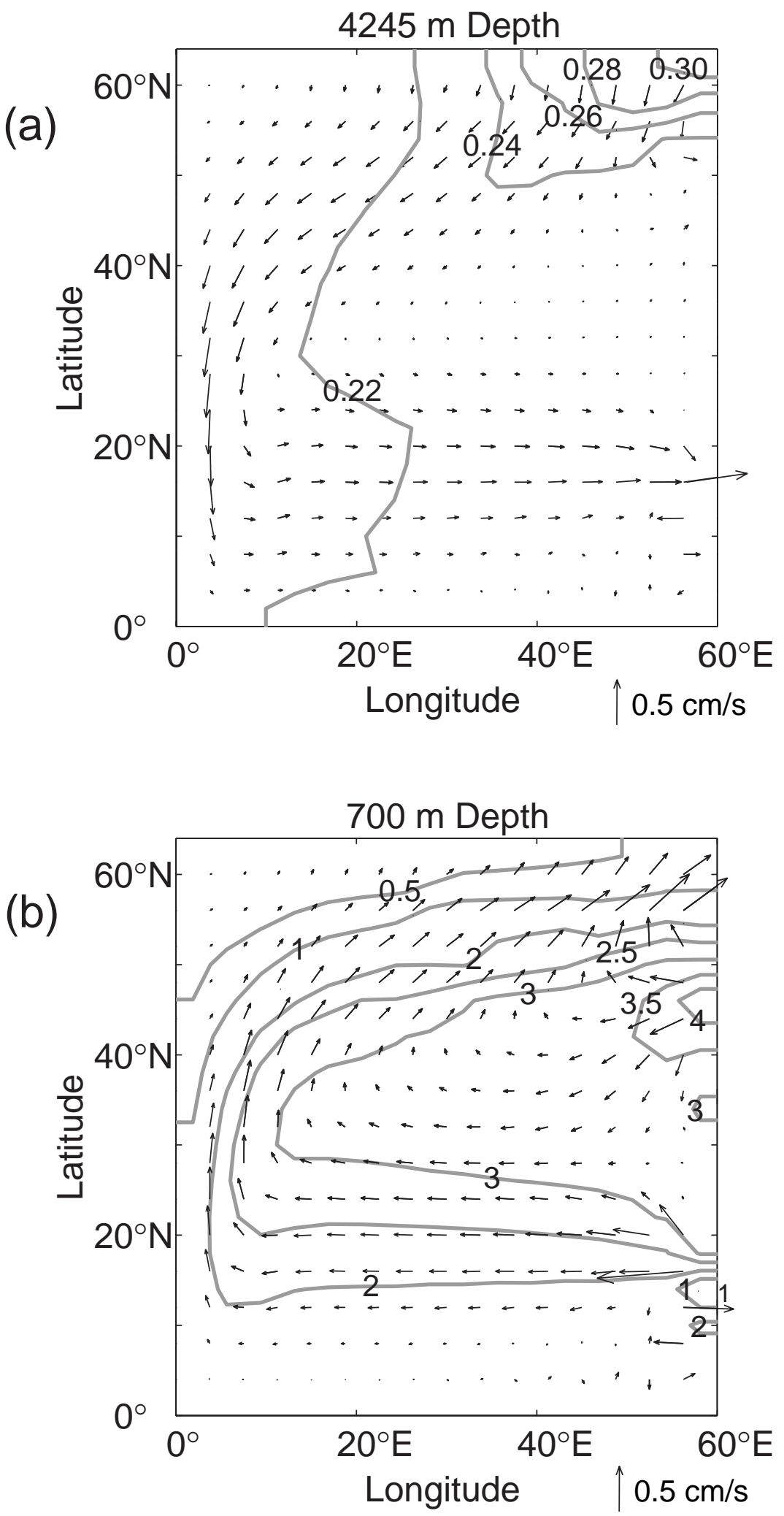

FIG.6. Plan view of the circulation and temperature (contours) with the mixing column located along the eastern boundary at $18^{\circ} \mathrm{N}$. (a) lowest model level (4245 $\mathrm{m}$ depth); (b) thermocline level (700 $\mathrm{m}$ depth). 

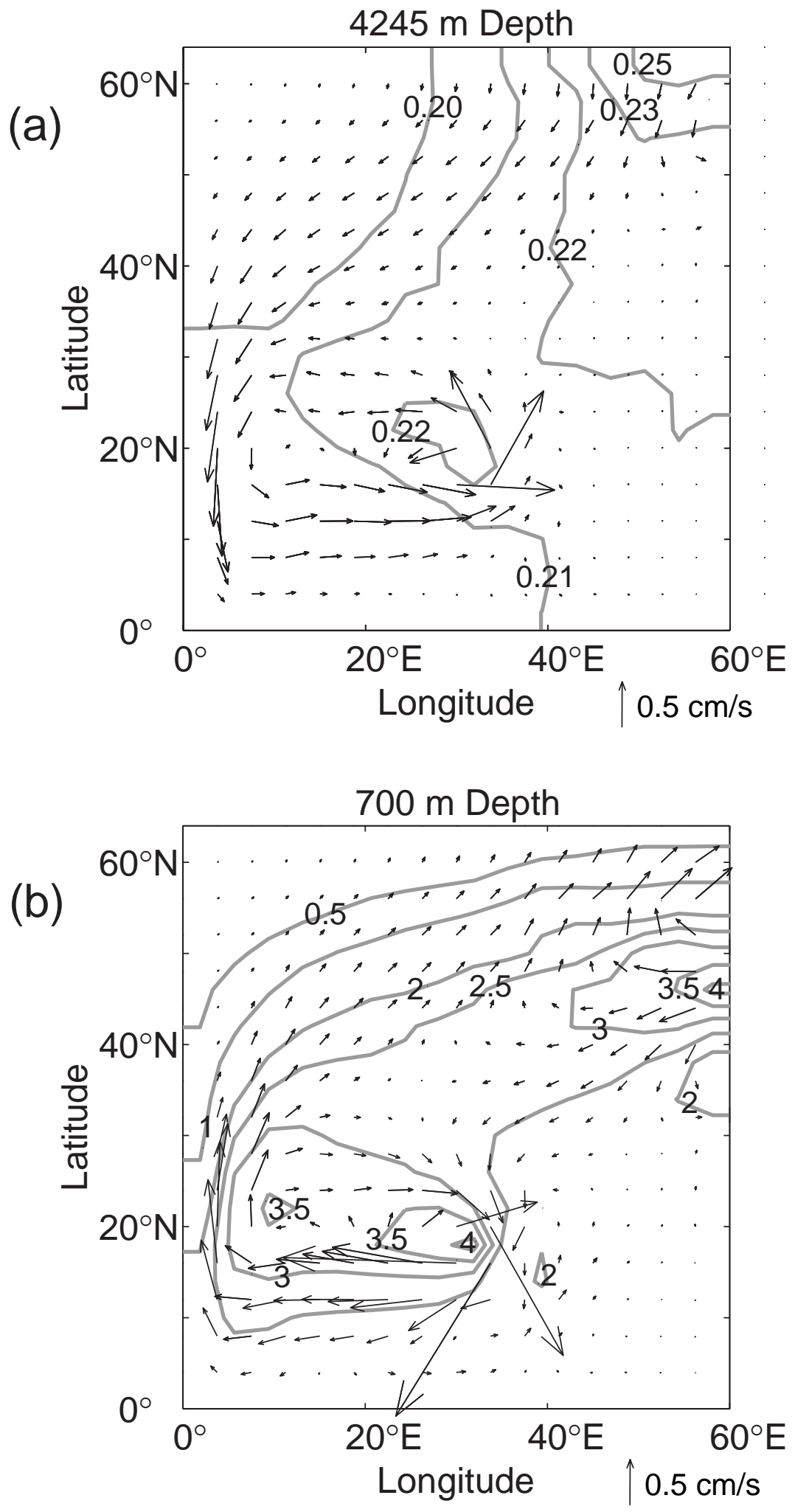

FIG.7. Plan view of the circulation and temperature (contours) with the mixing column located at mid-basin $\left(32^{\circ} \mathrm{E}\right)$ and $18^{\circ} \mathrm{N}$. (a) lowest model level (4245 m depth); (b) thermocline level (700 $\mathrm{m}$ depth). 


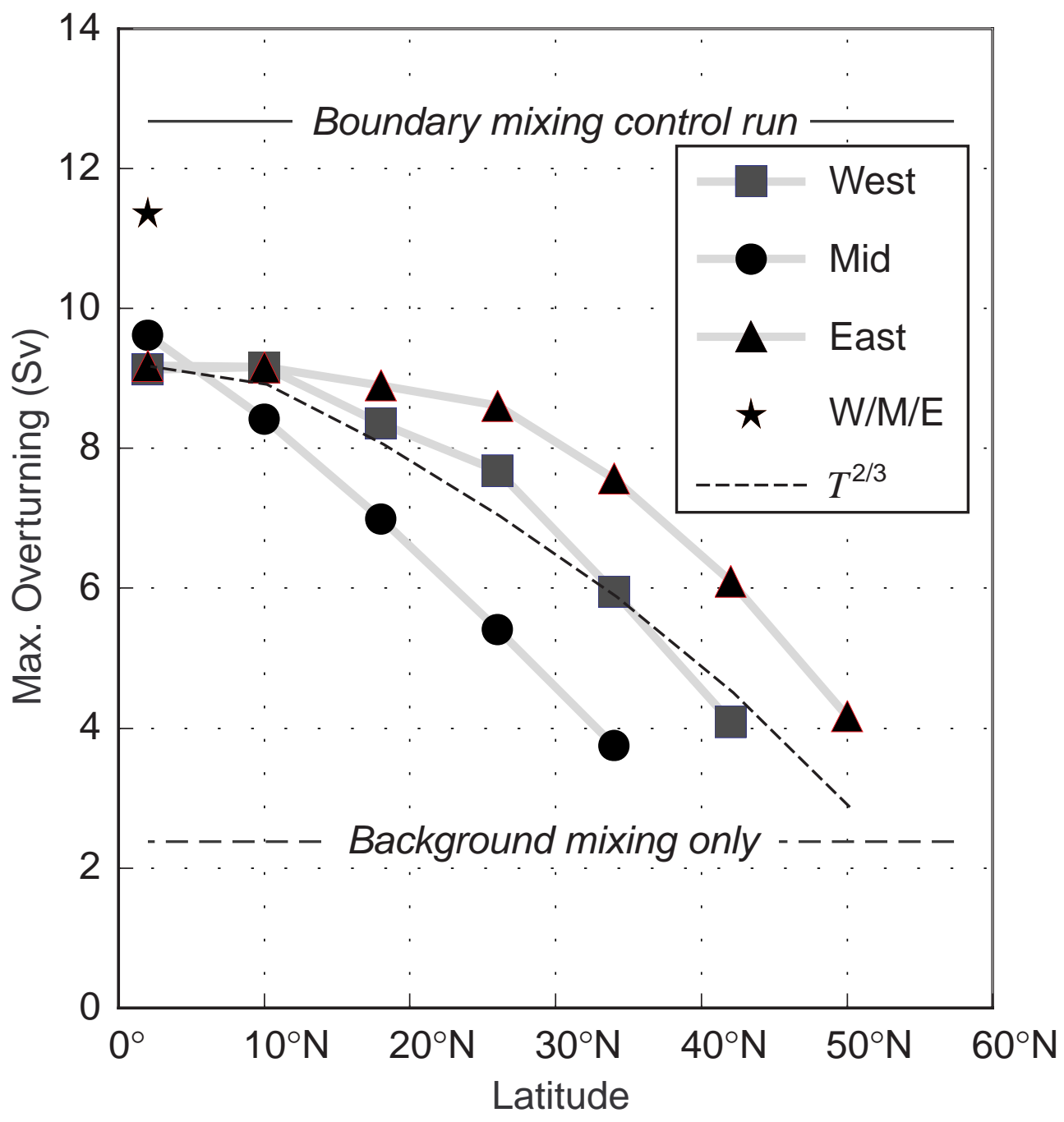

FIG.8. Maximum in overturning streamfunction for highly localized mixing experiments. The abscissa reflects the meridional location of the mixing column with $\kappa=160 \times 10^{-4} \mathrm{~m}^{2} \mathrm{~s}^{-1}$, otherwise the diffusivity is set to a background value of $\kappa=0.1 \times 10^{-4} \mathrm{~m}^{2} \mathrm{~s}^{-1}$ (these runs were done using $3.75^{\circ} \times 4^{\circ}$ resolution). The three series show results for different zonal locations of the mixing column, i.e., adjacent to the western wall, at mid-basin, and adjacent to the eastern wall. The ' $\star$ ' indicates the result when mixing is equally divided into three equatorial columns at these zonal locations. 


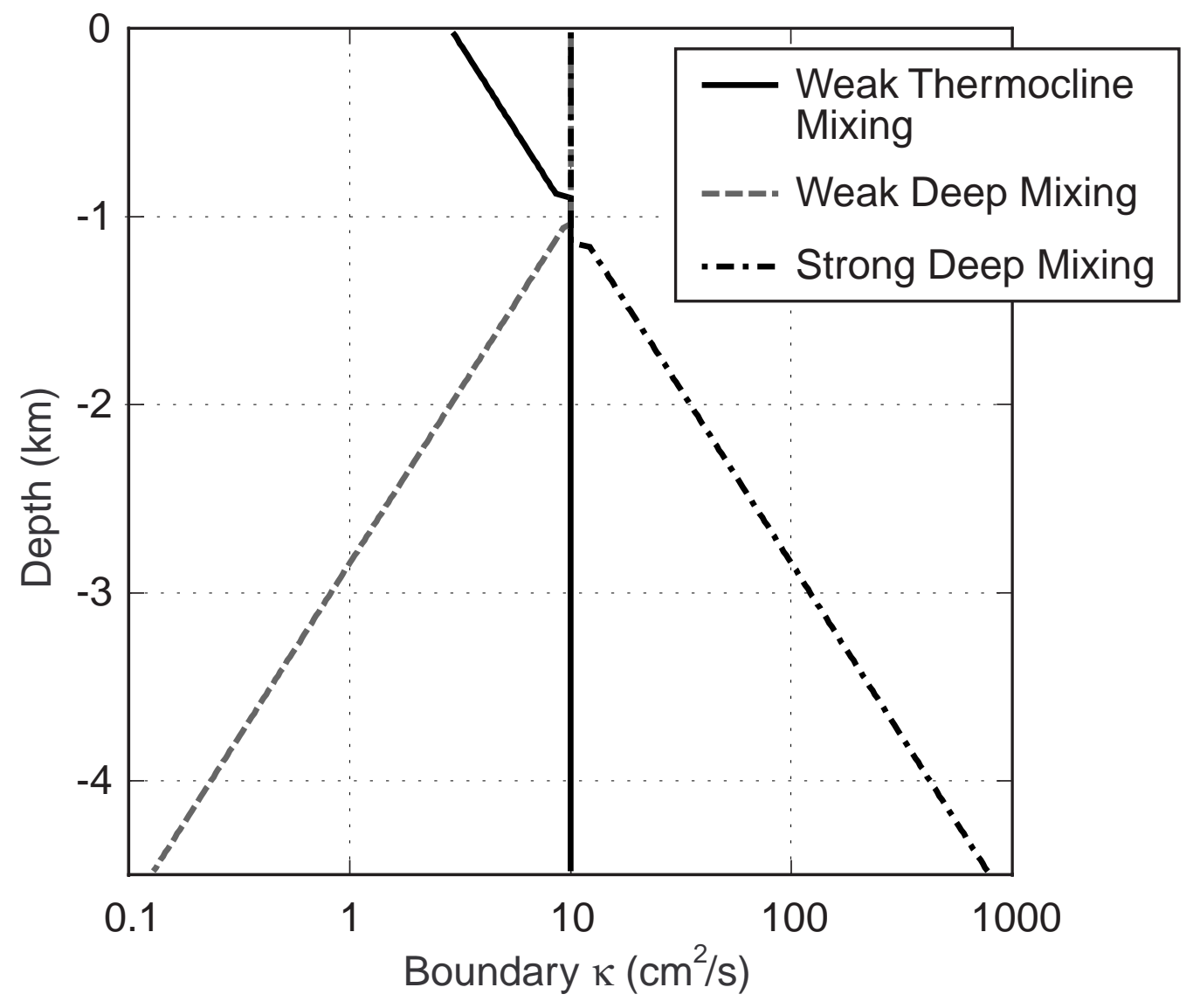

FIG.9. Vertical profile of boundary diapycnal diffusivity for weak thermocline mixing, weak deep mixing, and strong deep mixing experiments. 
(a)
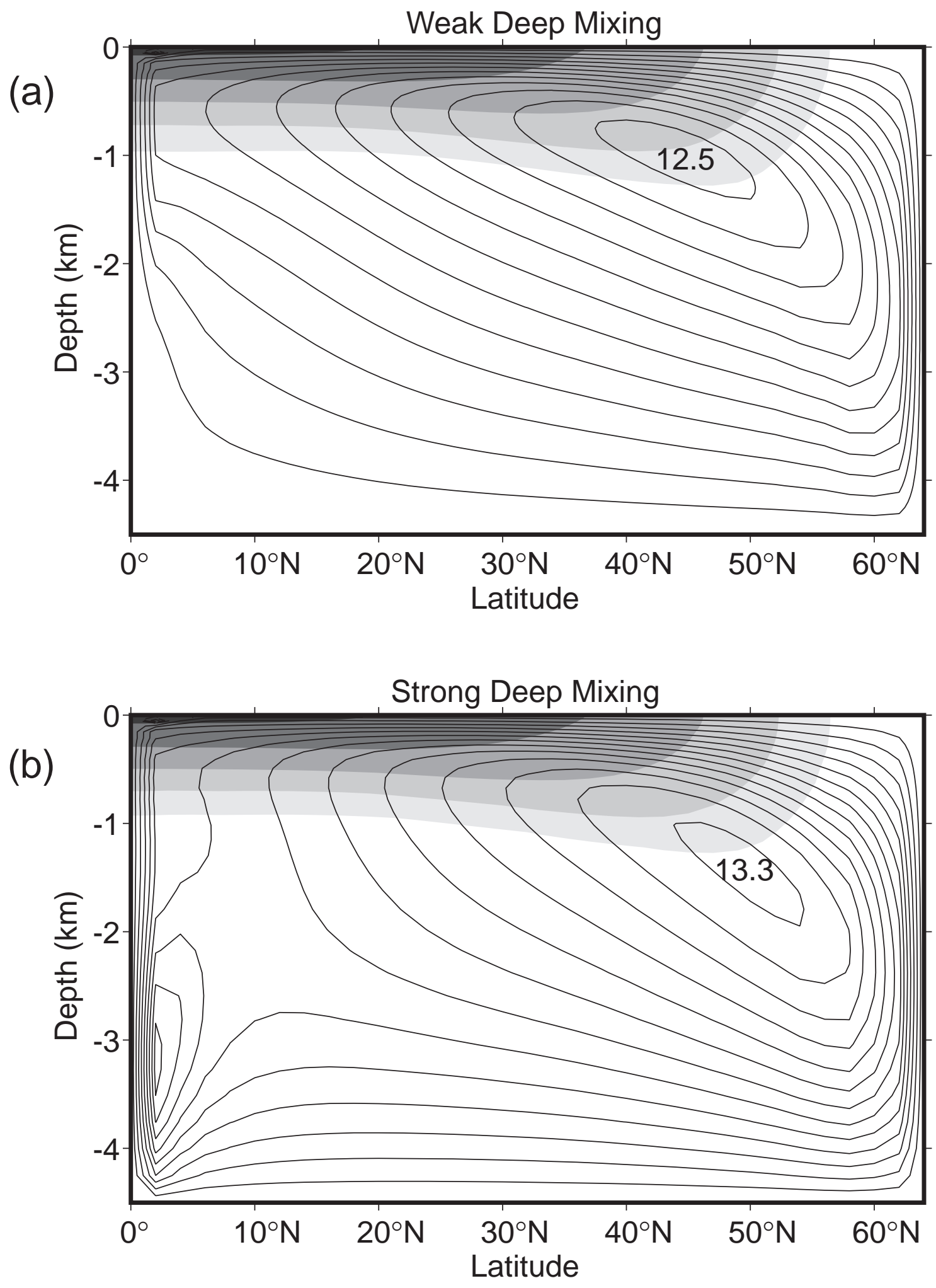

FIG.10. Meridional overturning streamfunction (contours) and zonally averaged temperature (shading) for (a) weak deep mixing and (b) strong deep mixing runs. 
(a)
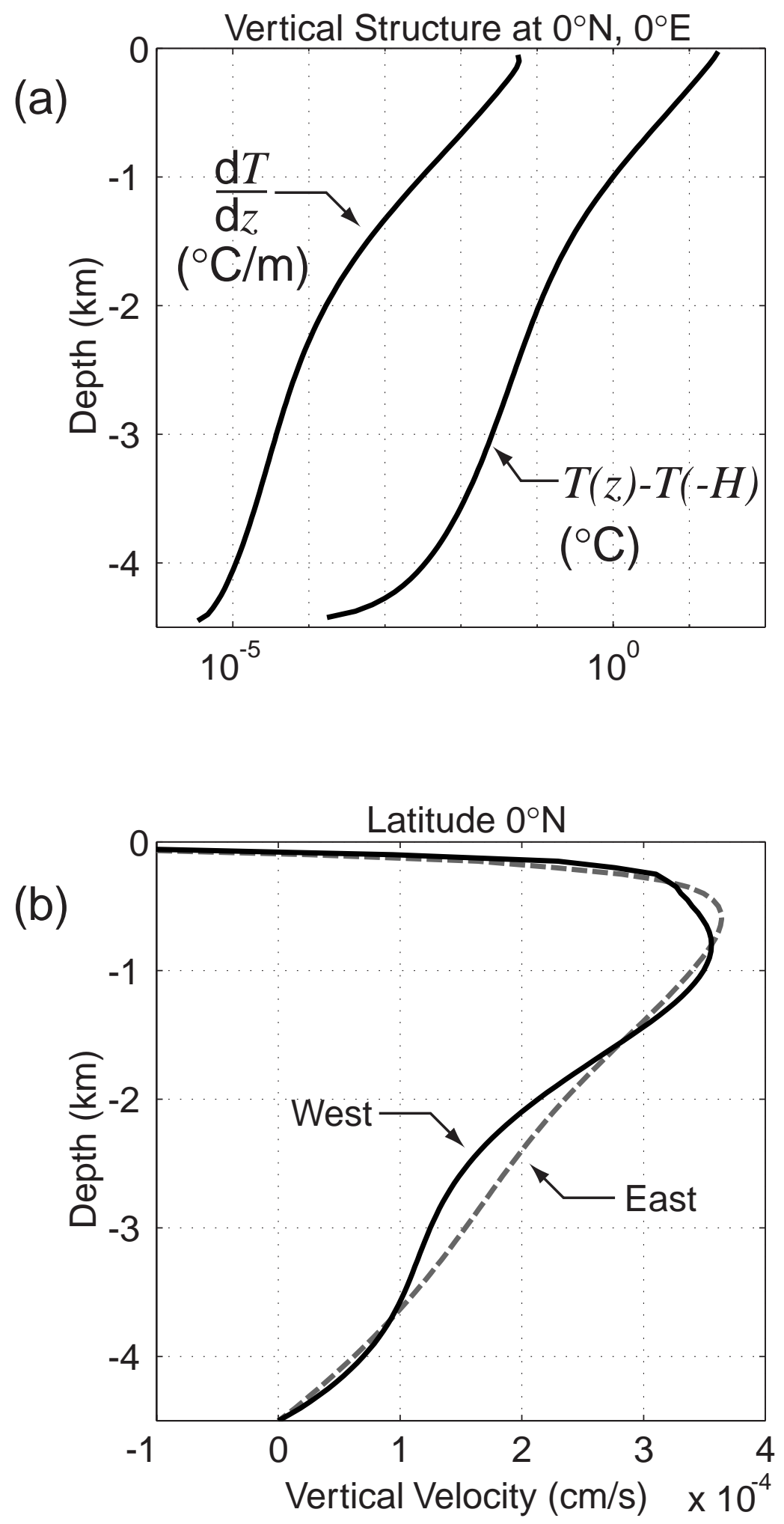

FIG.11. (a) Vertical potential temperature structure in low-latitudes along the boundary, as exemplified by this plot of $T(z)-T(-H)$ and $\mathrm{d} T / \mathrm{d} z$ at $0^{\circ} \mathrm{E}, 0^{\circ} \mathrm{N}$. (b) Vertical velocity adjacent to the equatorial boundary, as shown for the westmost and eastmost gridpoints. 


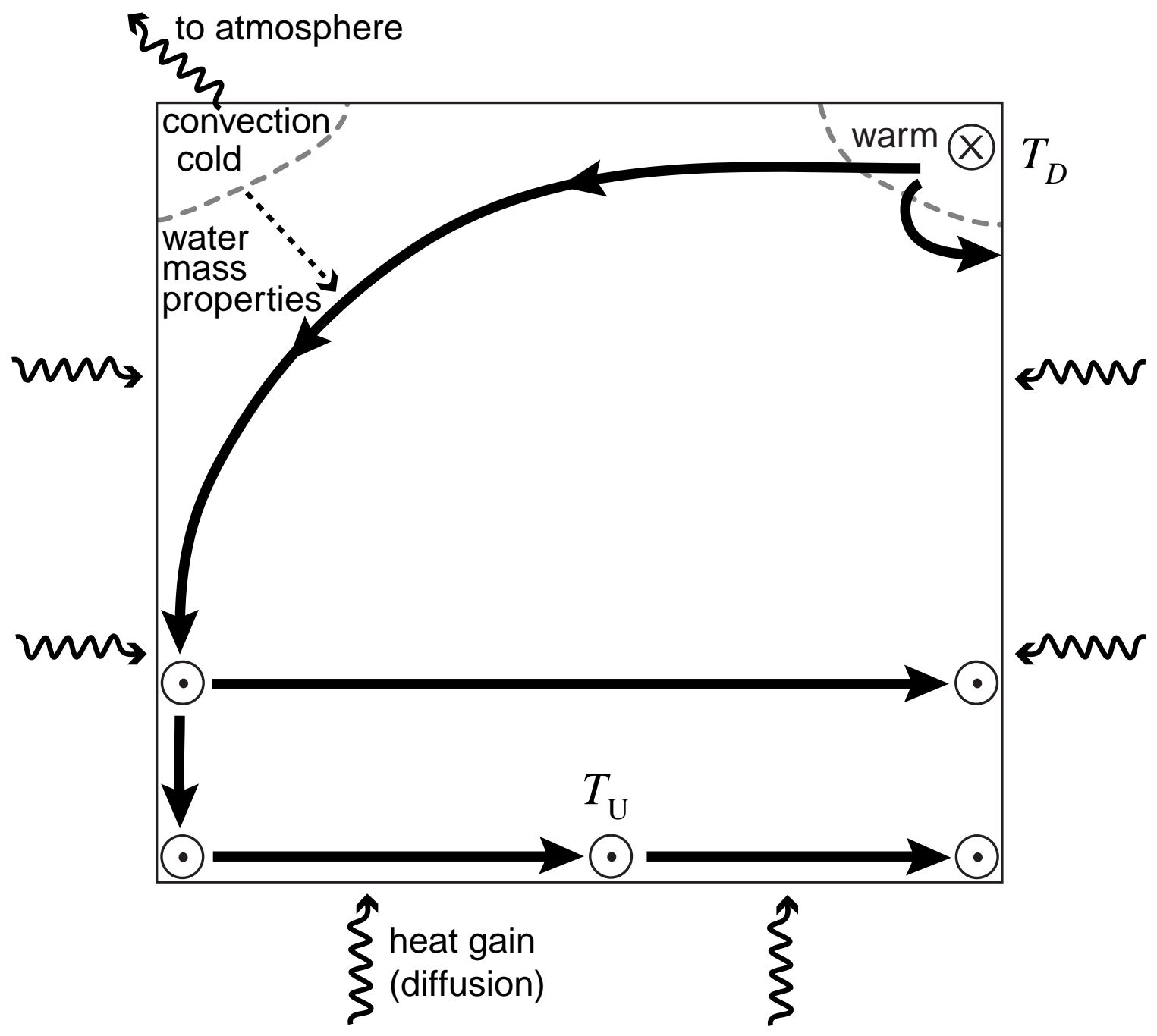

FIG.12. Illustration (plan view) of abyssal flow and heat budget. Flow downwells (as indicated by the circled ' $\mathrm{X}$ ') in the northeast corner at temperature $T_{\mathrm{D}}$ and its water mass properties are subsequently modified as it flows adjacent to deep convection in the northwest. Flow then proceeds along the western boundary; some flow upwells (as indicated by the circled ' $\bullet$ ') in the western boundary, some flow reaches the equator and upwells, and some flow moves acoss the basin before upwelling in the east. Downward diffusion of heat along the boundaries is not quite balanced by upwelling so that the flow is warmed slightly in low-latitudes, upwelling at average temperature $T_{\mathrm{U}}$. 
(a)
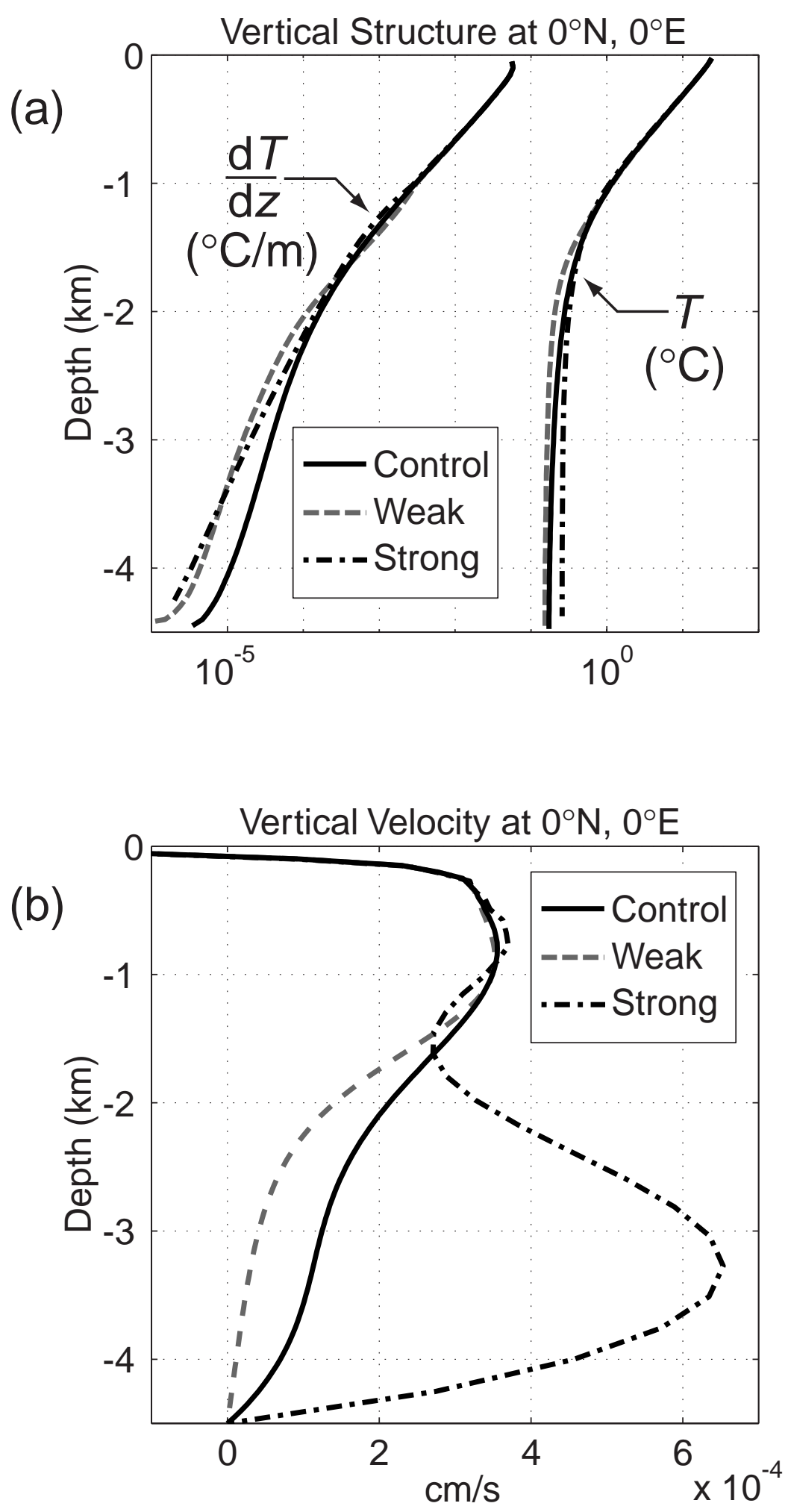

FIG.13. (a) Vertical potential temperature structure and (b) vertical velocity at the western extreme of the equator for the control boundary mixing, weak deep mixing, and strong deep mixing runs. 
(a)
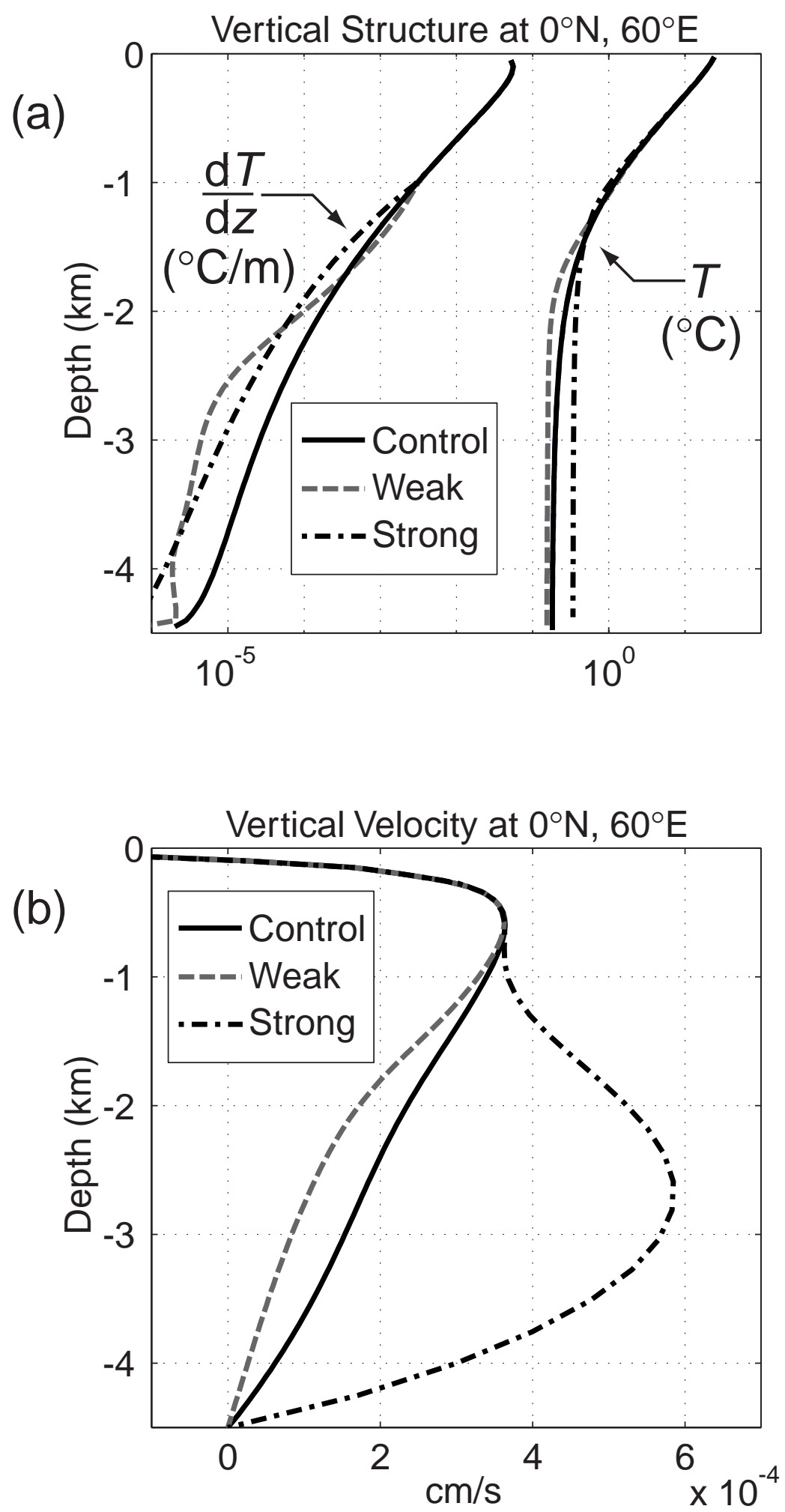

FIG.14. (a) Vertical potential temperature structure and (b) vertical velocity at the eastern extreme of the equator for the control boundary mixing, weak deep mixing, and strong deep mixing runs. 
(a)

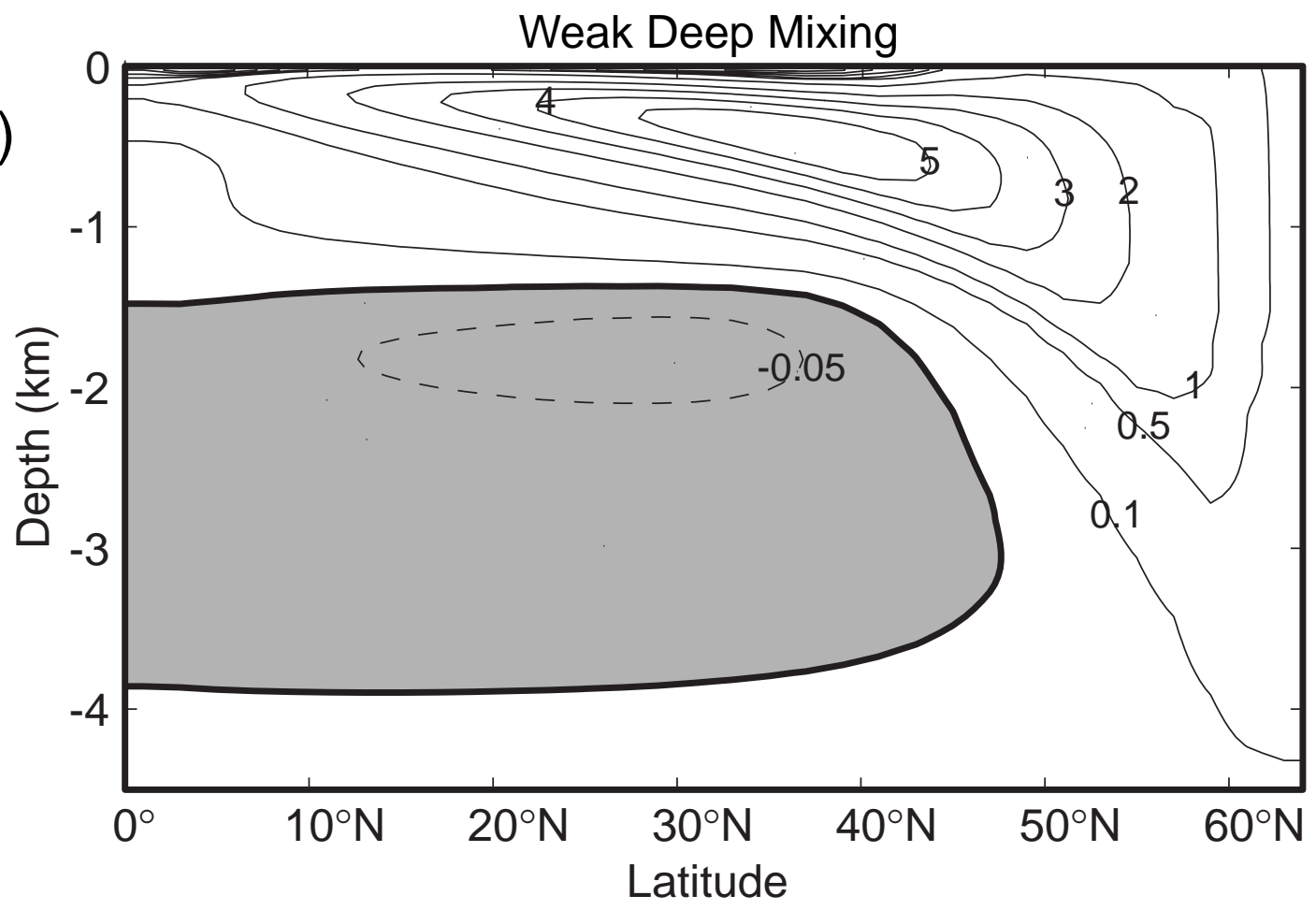

(b)

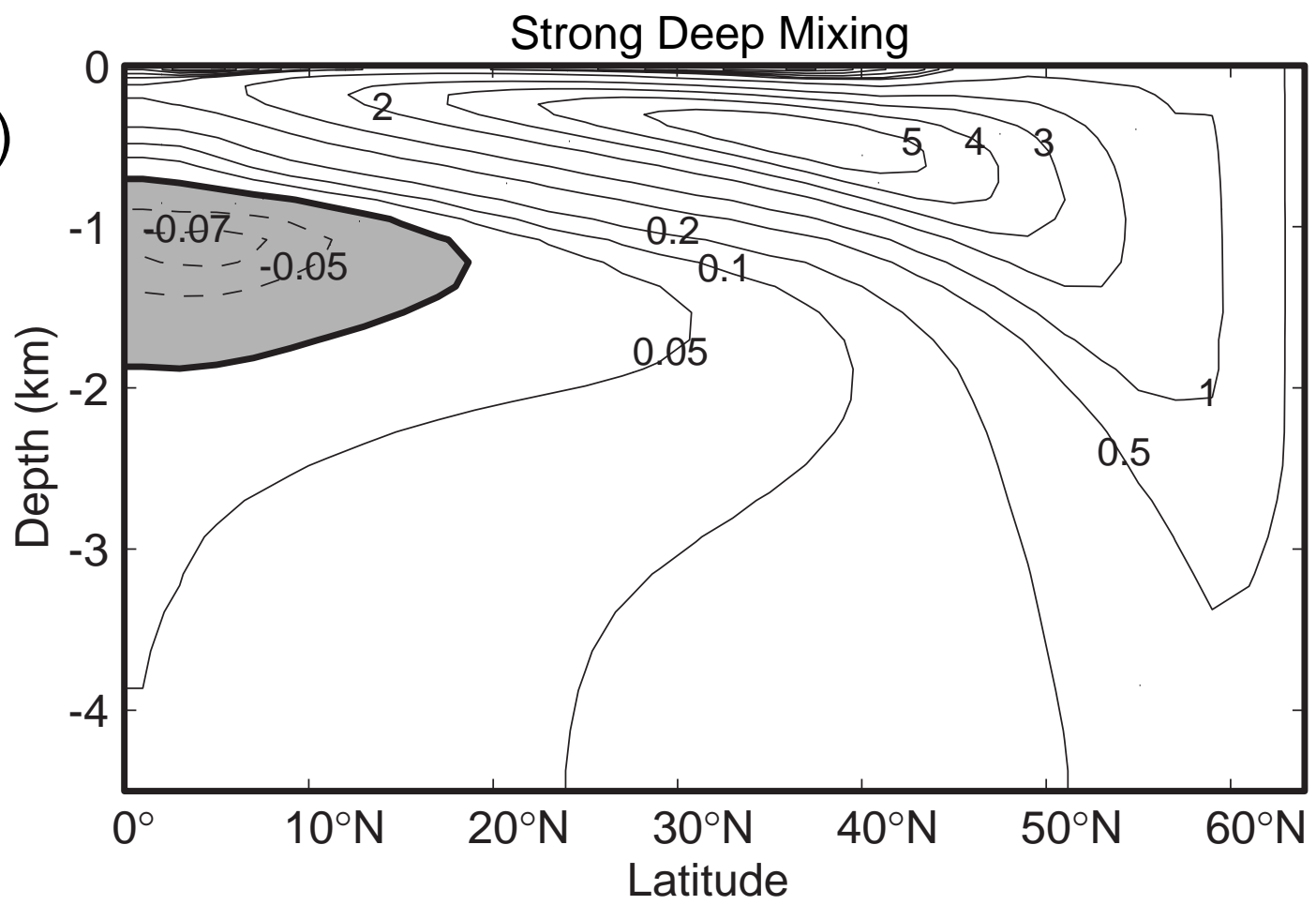

FIG.15. Potential temperature difference between the eastern and western boundary for (a) weak deep mixing and (b) strong deep mixing runs. The difference is negative in shaded areas. 